\title{
协同催化模式在金属铱催化不对称烯丙基取代反应中的应用研究进展
}

\author{
田飞张 键 ${ }^{\dagger}$ 杨武林* 邓卫平* \\ (华东理工大学药学院 上海市新药设计重点实验室 上海 200237)
}

\begin{abstract}
摘要 铱催化不对称烯丙基取代反应因其特殊的支链区域选择性和优秀的对映选择性已成为合成手性化合物的重要 方法之一. 采用铱/其他催化剂(有机小分子、过渡金属)协同催化体系能进一步拓宽亲核试剂的类型, 并且通过对两种催 化剂的调控有可能提高反应的对映选择性，甚至实现多手性中心产物的立体发散性合成. 综述了金属铱与有机小分子 或其他过渡金属协同催化的不对称烯丙基化反应研究进展. 按照催化剂的类型(有机胺催化剂、相转移催化剂、布朗斯 特酸、路易斯碱、过渡金属)对这些反应进行了梳理和总结，同时对代表性反应的机理以及该领域仍然存在的问题与未 来发展进行了简单阐述.
\end{abstract}

关键词 不对称催化; 烯丙基取代反应; 铱催化剂; 协同催化

\section{Progress in Iridium-Catalyzed Asymmetric Allylic Substitution Reactions via Synergetic Catalysis}

\author{
Tian, Fei $^{\dagger} \quad$ Zhang, Jian ${ }^{\dagger} \quad$ Yang, Wulin* Deng, Weiping* \\ (School of Pharmacy and Shanghai Key Laboratory of New Drug Design, East China University of Science and \\ Technology, Shanghai 200237)
}

\begin{abstract}
Iridium-catalyzed asymmetric allylic substitution reaction has become one of the most important methods for the synthesis of chiral compounds due to its exceptional branched regioselectivity and excellent enantioselectivity. The scope of nucleophiles will be further expanded by synergetic catalysis system of iridium and other catalysts (organocatalysts, other transition metal catalysts). Besides, it is possible to improve the enantioselectivity of the reaction and even realize the stereodivergent synthesis of the products with multiple stereocenters. The progress in the field of catalytic asymmetric allylic substitutions through synergetic iridium and organocatalysis or other transition metal catalysis is summarized. These reactions are classified according to the types of catalysts (aminocatalyst, phase transfer catalyst, Brønsted acid, Lewis base, transition metal). Meanwhile, the mechanism of representative reactions, the existing problems and the prospects in this area are briefly described. Keywords asymmetric catalysis; allylic substitution reaction; iridium catalyst; synergetic catalysis
\end{abstract}

烯丙基取代反应是指亲核试剂对烯丙基亲电试剂 发生形式上的 $\mathrm{S}_{\mathrm{N}} 2$ 或者 $\mathrm{S}_{\mathrm{N}} 2$ 的取代反应，而这些反应通

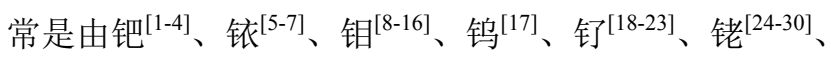
镍 ${ }^{[31-33]}$ 、铜 ${ }^{[34-42]}$ 等过渡金属来催化完成的. 1965 年, Tsuji 等 ${ }^{[43]}$ 报道了等物质的量的 $\pi$-烯丙基氯化钯与丙二酸二 乙酯钠盐发生的亲核取代反应. 1977 年, Trost 课题组 ${ }^{[44]}$ 使用钯/手性磷配体催化体系首次实现了催化不对称烯 丙基取代反应. 随后，经过数十年的发展，过渡金属催
化的不对称烯丙基取代反应已经成为有机合成中构建 碳碳键和碳杂键最重要的方法之一, 在手性药物和天然 产物的不对称合成有着广泛的应用 ${ }^{[45-47]}$.

在众多过渡金属催化的烯丙基取代反应中，金属 铱、钿、铇、钓、铑等催化的烯丙基取代反应有着不同 于钯的特殊的支链区域选择性(Scheme 1), 其中金属铱 在该类反应中表现出优异的对映选择性，在近年来越来 越多地受到化学家们的关注. 1997 年, Takeuchi 课题

\footnotetext{
* Corresponding authors. E-mail: yangwl@ecust.edu.cn; weiping_deng@ecust.edu.cn

Received May 4, 2020; revised May 23, 2020; published online May 29, 2020

Dedicated to Professor Henry N. C. Wong on the occasion of his 70th birthday.

Project supported by the National Natural Science Foundation of China (Nos. 21772038, 21901072), the Fundamental Research Funds for the Central Universities (No. 222201814048) and the Shanghai Sailing Program (No. 18YF140560).

国家自然科学基金(Nos. 21772038, 21901072)、中央高校基本科研业务费(No. 222201814048)和上海市青年科技英才扬帆计划(No. 18YF140560)资助项 目.

$\dagger$ 共同第一作者(These authors contributed equally to this work).
} 
组 ${ }^{[48]}$ 报道了金属铱催化的烯丙基取代反应. 同年, Helmechen 课题组 ${ }^{[49}$ 报道了第一例金属铱催化的不对称烯 丙基取代反应，通过使用 PHOX 配体可以取得 99/1 的区 域选择性和 $95 \%$ ee 的对映选择性. 此后, 国内外 Helmchen、Hartwig、Carreira、Alexakis、游书力等多个课题 组 ${ }^{[50-54]}$ 均在该领域进行了深入研究, 各种各样的亲核试 剂被成功运用到金属铱催化的不对称烯丙基取代反应 中, 以非常优秀的区域选择性和对映选择性得到了结构 多样的含烯丙基模块的手性产物. 尽管如此, 由于铱催 化的烯丙基取代反应独特的支链选择性, 其产物通常含 有多个手性中心(两个及以上), 如何实现高效的立体发 散性合成依然是该领域的重要挑战.

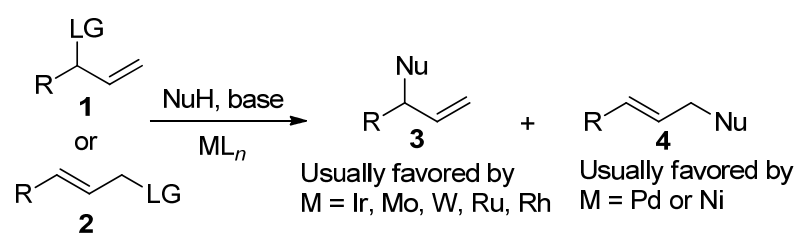

图式 1 过渡金属催化烯丙基取代反应的区域选择性

Scheme 1 Regioselectivity of transition metal-catalyzed allylic substitution reactions

两种或者多种催化剂参与的协同催化模式 ${ }^{[55-63]}$, 因 其具有简便、高效等优点而引起了化学家们的极大兴趣 (Scheme 2). 在这种催化模式中, 多种催化剂共存于同 一反应体系中，催化剂之间互相补充、协同作用，彼此 间不干扰, 每种催化剂选择性地平行作用于相应的反应 底物或者催化循环, 进而顺利实现了各个反应底物的有 序组装, 为许多以前无法实现的转化提供了新的解决方 案. 体系中的任意一种催化剂都可发挥手性诱导作用, 因此当手性催化剂的不对称诱导相互匹配时, 有利于提 高反应的对映选择性, 并且能够实现连续多个手性中心 的立体化学控制, 对手性化合物的立体发散合成具有重 要意义。

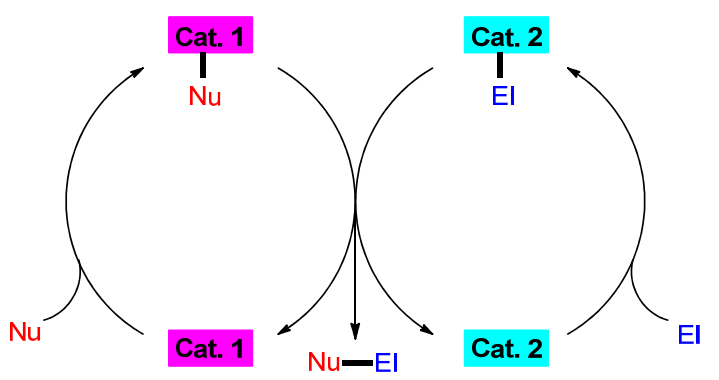

图式 2 协同催化模式

Scheme 2 Model of synergetic catalysis

鉴于协同催化模式的独特优势, 将这种催化模式应 用到金属铱催化的不对称烯丙基化反应中, 能够大大丰 富亲核试剂的类型，拓宽烯丙基取代反应的应用范围. 更为重要的是, 当两种催化剂都具有手性环境时, 则有
可能实现多手性中心产物的立体发散性合成.

本综述将总结协同催化模式在金属铱催化不对称 烯丙基取代反应中的应用研究进展，并根据协同催化剂 类型的不同，将按照以下几个方面进行展开：(1)金属铱 与有机胺协同催化，(2)金属铱与相转移催化剂协同催 化，(3)金属铱与布朗斯特酸协同催化，(4)金属铱与路易 斯碱协同催化, (5)金属铱与其他过渡金属协同催化.

\section{1 金属铱与有机胺协同催化}

有机胺催化是有机小分子催化领域的一类重要分 支 ${ }^{[64-66]}$, 包括伯胺、仲胺和叔胺催化三种类型, 伯胺和 仲胺主要通过与醛或酮类底物形成烯胺或亚胺中间体 参与反应, 而叔胺在催化反应时常作为路易斯碱发挥作 用. 近年来, 化学家们发现有机胺与过渡金属在反应体 系中可以共存，且分别发挥活化作用，据此报道了一系 列过渡金属与有机胺协同催化的不对称反应，是协同催 化领域发展最为迅速的一个研究方向 ${ }^{[67-68]}$.

2006 年, Córdova 课题组 ${ }^{[69]}$ 报道了首例过渡金属与 有机胺协同催化的例子. 他们选用钯和吡咯烷作催化 剂，实现了醛、酮分子间羰基 $\alpha$ 位的烯丙基化反应. 在 此之后过渡金属与有机胺的协同催化模式得到了迅速 的发展.

2013 年, Carreira 课题组 ${ }^{[70]}$ 报道了首例金属铱与手 性胺协同催化反应，通过联合使用手性铱催化剂(采用 自主设计的磷一烯配体)和金鸡纳碱衍生的伯胺催化剂, 成功实现了支链醛类化合物 $\alpha$ 位的不对称烯丙基取代反 应. 在此反应中, 通过改变金属铱催化剂配体和伯胺催 化剂的立体构型，能够以良好的收率、完美的对映选择 性及非对映选择性获得目标产物的四种全部立体异构 体(Scheme 3)。控制实验表明，金属铱络合物活化支链 烯丙醇生成 $\pi$-烯丙基铱中间体，伯胺催化剂活化醛生成 烯胺活性中间体，随后两类中间体发生烯丙基取代反应 得到目标产物, 并且铱催化剂与伯胺催化剂分别控制产 物 $\alpha$ 和 $\beta$ 位的立体构型(Scheme 4).

在上述研究工作的基础上，该课题组后续利用类似 的金属铱与有机胺的协同催化体系，实现了不同类型醛 类化合物的不对称烯丙基取代反应，并成功应用于多种 生物活性分子和药物的不对称合成中. 2014 年, Carreira 课题组 ${ }^{[71]}$ 尝试利用相同的催化策略来实现直链烷基醛 的 $\alpha$ 位不对称烯丙基取代反应，但该反应存在一个不容 忽视的挑战: 目标产物的一个手性中心含有易于差向异 构化的羰基 $\alpha$ 位氢原子. 通过系统性的条件优化, 作者 发现脯氨酸衍生的手性仲胺催化剂可以高效地活化直 链烷基醛, 实现铱和有机胺协同催化的不对称烯丙基取 代反应. 同样, 通过改变手性配体和仲胺催化剂的立体 


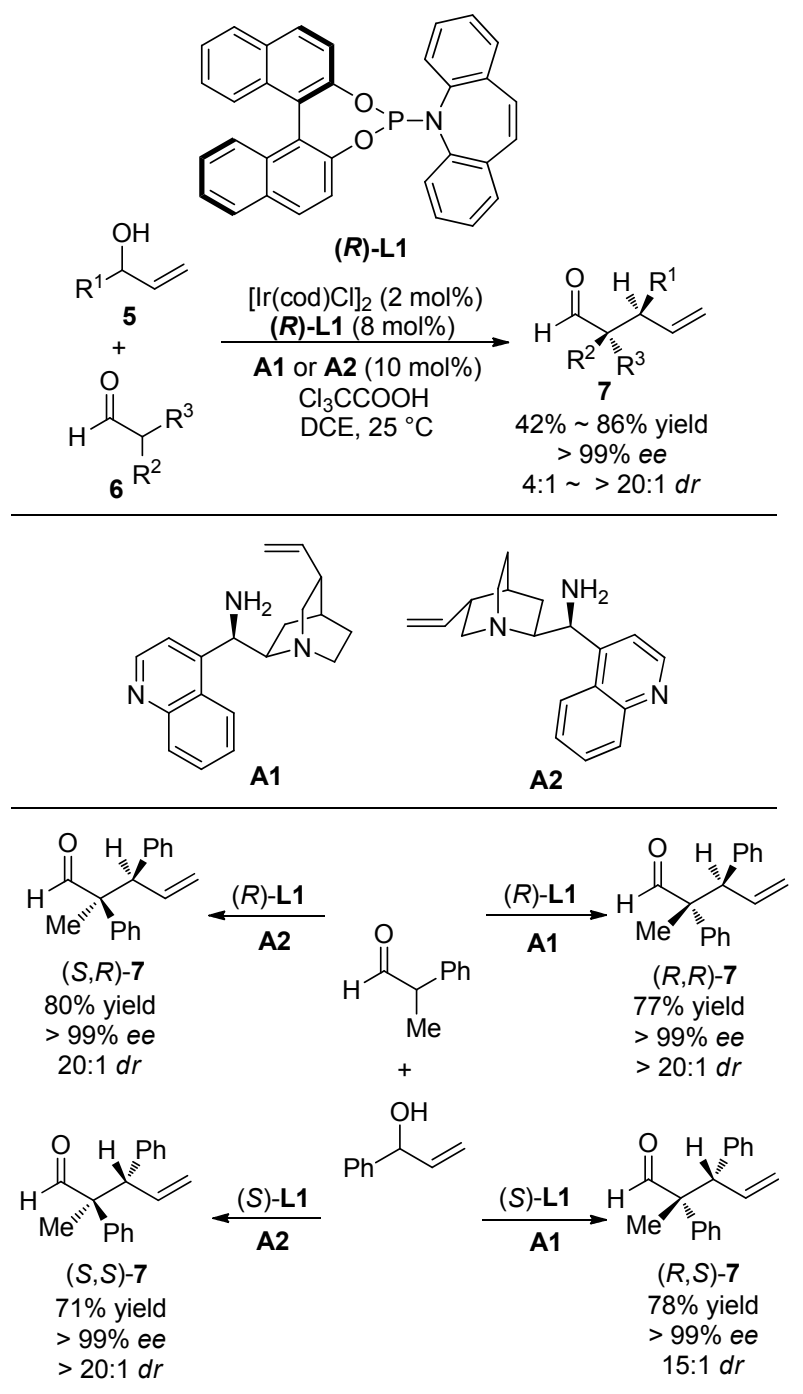

图式 3 铱/伯胺协同催化: 支链醛的不对称 $\alpha$-烯丙基化

Scheme 3 Synergetic Ir/primary amine catalysis: asymmetric $\alpha$-allylations of branched aldehydes

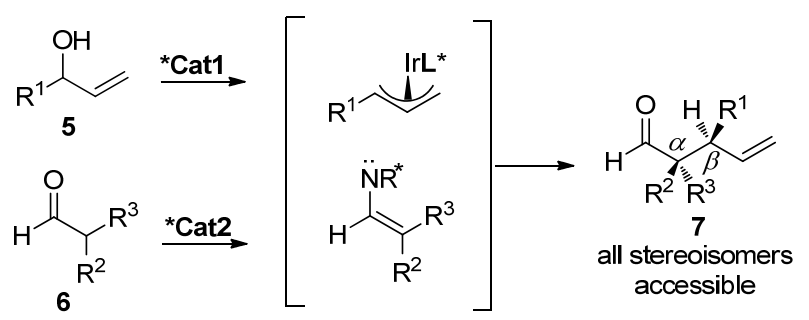

图式 4 铱/有机胺协同催化机理

Scheme 4 Mechanism of synergetic Ir/amine catalysis

构型, 反应也能够以良好的收率、优秀的立体选择性得 到目标产物的全部立体异构体. 此外，作者还将该方法 应用于抗抑郁药物帕罗西汀的不对称合成中(Scheme $5)$.

同年, Carreira 课题组 ${ }^{[72]}$ 通过对反应底物的设计, 成 功的将该协同催化策略应用于天然产物 $\Delta^{9}$-tetrahydro-

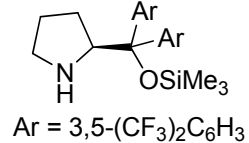

(S)-A3<smiles>[R]CC=[O+][C-]C=C</smiles>
$[\operatorname{lr}(\operatorname{cod}) \mathrm{Cl}]_{2}(2 \mathrm{~mol} \%)$ L1 (8 $\mathrm{mol} \%)$ A3 (10 mol\%) $(\mathrm{MeO})_{2} \mathrm{PO}_{2} \mathrm{H}$ DCE, r.t.

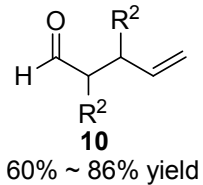

$>99 \%$ ee
$60 \% \sim 86 \%$ yield $3.5: 1->20: 1 d r$

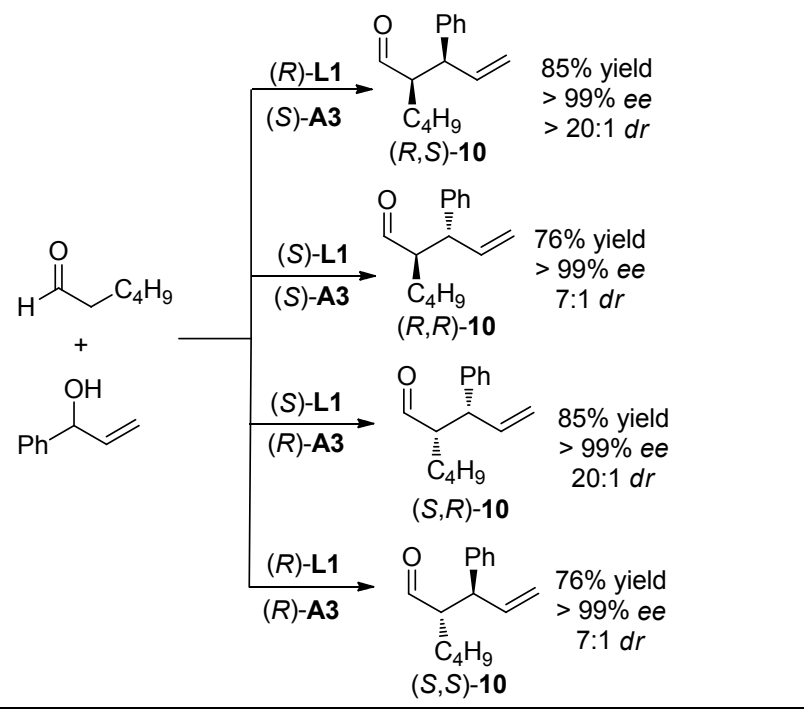<smiles>C=CC(O)c1ccc(F)cc1</smiles><smiles>C=C[C@H](CN=[PH2])C(C=O)(C=O)c1ccc(F)cc1</smiles>
$64 \%$ yield; > 99\% ee; $6: 1 d r$<smiles>CC#CCCCCCCCCCOc1ccc2c(c1)OCO2</smiles>

(-)-paroxetine

图式 5 铱/仲胺协同催化: 直链醛的不对称 $\alpha$-烯丙基化 Scheme 5 Synergetic Ir/secondary amine catalysis: asymmetric $\alpha$-allylations of linear aldehydes

cannabinols 的不对称合成中. 需要指出的是, 通过改变 手性催化剂的立体构型，可以方便的得到该天然产物的 所有立体异构体(Scheme 6).

2015 年, Carreira 课题组 ${ }^{[73]}$ 再次利用金属铱与手性 仲胺协同催化体系实现了 $\alpha$-氨基乙醛和 $\alpha$-羟基乙醛的 不对称烯丙基取代反应，以良好的收率、优秀的立体选 择性合成了一系列 $\alpha$ 位杂原子(氮、氧)取代的 $\gamma, \delta$-不饱 和醛类化合物，并且通过手性配体与仲胺催化剂不同绝 对构型的组合能够实现 $\gamma, \delta$-不饱和醛 16 的全部 4 种立体 异构体发散性合成(Scheme 7). 
<smiles>C=CC(O)c1c(OC)cc(C=S)cc1OC</smiles>

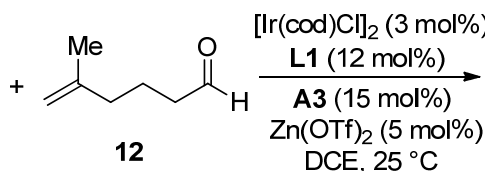

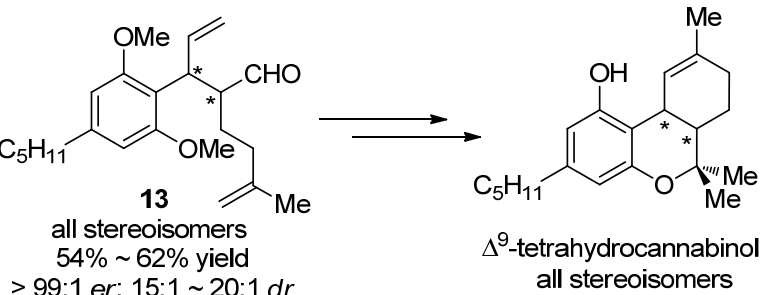

图式 $6 \Delta^{9}$-tetrahydrocannabinol 所有异构体的立体发散性合 成

Scheme 6 Stereodivergent preparation of all stereoisomers of $\Delta^{9}$-tetrahydrocannabinol

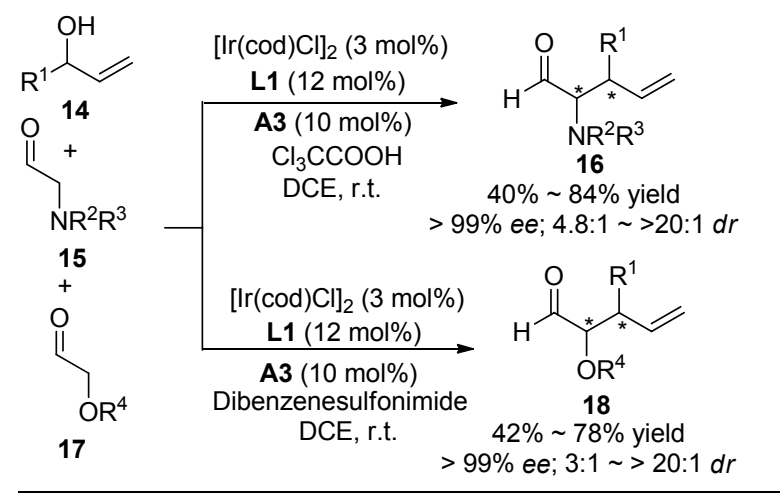

(S)-L1, (R)-A3 (S)-L1, (S)-A3 (R)-L1, (S)-A3 $\quad(R)$-L1, (R)-A3

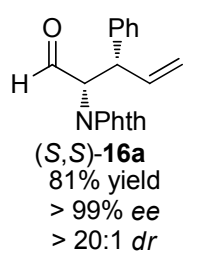

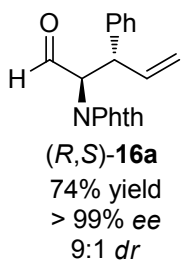
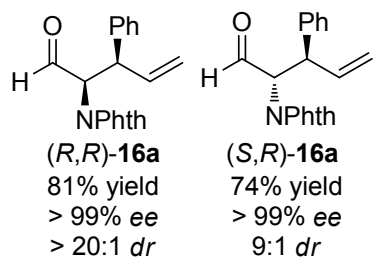

图式 7 铱/仲胺协同催化: $\alpha$-氨基(羟基)乙醛的不对称烯丙基 化

Scheme 7 Synergetic Ir/secondary amine catalysis: asymmetric $\alpha$-allylations of $\alpha$-amino- and $\alpha$-hydroxyacetaldehydes

自然界中存在许多不稳定或者易挥发的亲核试剂, 如肼、羟胺、叔丁基过氧化物及小分子醛类化合物等，此 类化合物由于其不稳定性, 常储存于水溶液中. 但过量 的水(具有亲核性)会淬灭过渡金属活性中间体 ${ }^{[74]}$, 从而 限制了此类化合物在有机合成中的应用. 因此，若要实 现此类化合物的烯丙基取代反应，就必须保证水对 $\pi$-烯 丙基金属中间体的亲核加成反应是非动力学优势的或 可逆的. 2019 年, Carreira 课题组 ${ }^{[75]}$ 利用金属铱与仲胺协 同催化体系成功实现了 $\alpha$-氯乙醛、戊二醛等的不对称烯 丙基取代反应, 并以良好的收率、优秀的立体选择性合 成了一系列烯丙基化产物. 近期, 该课题组利用类似的 协同催化策略, 实现了乙醛(水溶液)的不对称烯丙基取
代反应, 并以此为关键步骤实现了 4 种倍半萜烯类天然 产物 heliannuols C (E) 和 heliespirones A (C)的不对称合 成(Scheme 8) ${ }^{[76]}$.

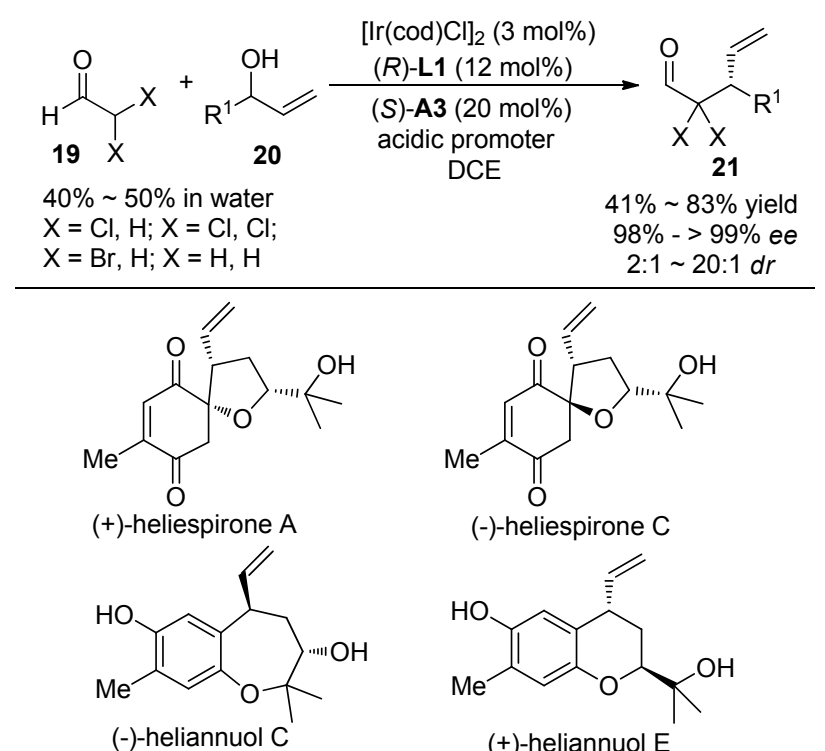

图式 8 铱/仲胺协同催化: 小分子醛的不对称烯丙基化

Scheme 8 Synergetic Ir/secondary amine catalysis: asymmetric allylation of small molecule aldehydes

除了以上介绍的 Carreira 课题组报道的一系列出色 研究成果外, 其他课题组在此领域同样有着重要贡献. 2015 年, Jørgensen 课题组 ${ }^{[77]}$ 利用过渡金属与手性仲胺 协同催化体系, 实现了 $\alpha, \beta$-不饱和醛 $\gamma$ 位的不对称烯丙 基取代反应：以支链烯丙醇 23 为底物，在金属铱催化下 专一性地得到支链烯丙基化产物 24, 而以肉桂醇羧酸 酯 25 为底物, 在金属钯作用下则专一性地得到了直链 烯丙基化产物 26, 两种反应体系均能取得较好的收率 和优异的对映选择性(Scheme 9).

杨玉荣课题组以吲哚基支链烯丙醇为原料，利用醛 类化合物 $\alpha$ 位不对称烯丙基取代反应为关键步骤, 高效 地合成了多种多环吲哚生物碱. 2018 年, 该课题组 ${ }^{[78]}$ 以 2-吲哚基支链烯丙醇为底物，在金属铱与手性仲胺协同 催化下, 实现了脂肪醛 $\alpha$ 位不对称烯丙基取代反应，并 高效地合成了具有羧肽酶抑制活性的天然产物(一)-actinophyllic acid (Scheme 10). 2019 年, 该课题组 ${ }^{[79]}$ 以 3-吲 哚基支链烯丙醇为原料，通过类似的不对称烯丙基取代 反应，实现了天然产物(一)-alstoscholarine 的不对称合 成(Scheme 11).

2019 年，肖文精、陆良秋等 ${ }^{[80}$ 运用金属铱与有机伯 胺协同催化策略, 实现了乙烯基氨基醇 33 与醛或 $\beta, \gamma-$ 不 饱和酮的不对称 $[4+2]$ 环加成反应. 醛在伯胺催化下形 成的烯胺中间体与金属铱活化的乙烯基氨基醇发生的 不对称 $[4+2]$ 环加成反应，能以良好的收率、良好至优 


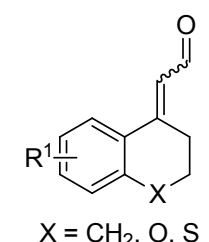
$\mathrm{X}=\mathrm{CH}_{2}, \mathrm{O}, \mathrm{S}$ (S)-A4 (20 mol\%) $(\mathrm{BuO})_{2} \mathrm{PO}_{2} \mathrm{H}(75 \mathrm{~mol} \%)$
DCE

$$
\mathrm{R}^{3}
$$$$
25
$$<smiles>c1ccc([PbH2]c2ccccc2)cc1</smiles>

(S)-A4

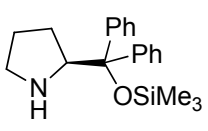

(S)-A5
$[\mathrm{Ir}(\operatorname{cod}) \mathrm{Cl}]_{2}(3 \mathrm{~mol} \%)$ (R)-L1 (12 mol\%)

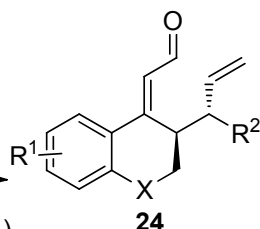

$40 \% \sim 78 \%$ yield $98 \% \sim>99 \%$ ee

$\left[\mathrm{Pd}\left(\mathrm{PPh}_{3}\right)_{4}\right](5 \mathrm{~mol} \%)$

L2 (12 mol\%)

(S)-A5 (20 mol\%) R $\mathrm{DCE}, 5^{\circ} \mathrm{C}$

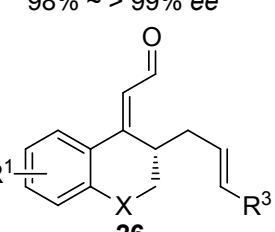
$64 \% \sim 84 \%$ yield $97 \% \sim>99 \%$ ee
图式 9 铱(钯)/仲胺协同催化: $\alpha, \beta$-不饱和醛的 $\gamma$ 位不对称烯丙 基化

Scheme 9 Synergetic $\operatorname{Ir}(\mathrm{Pd}) /$ secondary amine catalysis: asymmetric $\gamma$-allylations of $\alpha, \beta$-unsaturated aldehydes

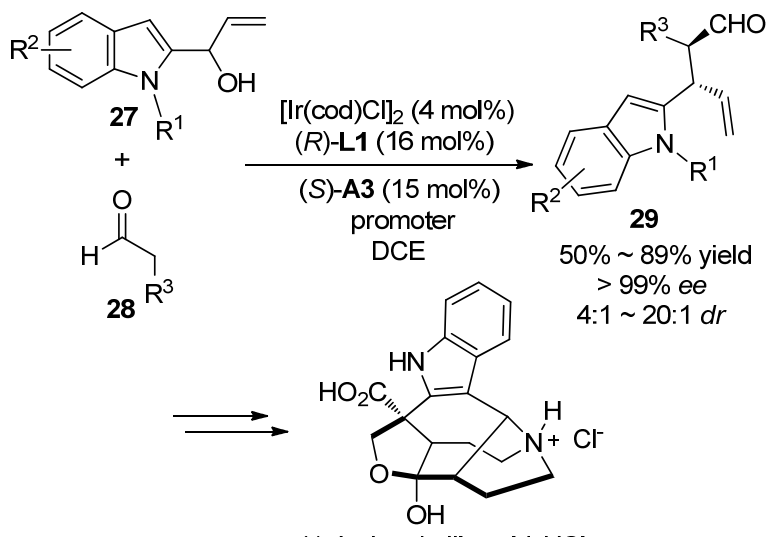

(-)-Actinophyllic acid•HCl

图式 10 吲哚烯丙基醇的双催化烯丙基化

Scheme 10 Dual catalytic allylation of indole-based allylic alcohol

秀的对映选择性和非对映选择性得到一系列光学纯的 二氢喹啉酮(Scheme 12). 需要指出的是, 该反应的关键 中间体半缩醛 36a 通过 “一锅法” 能以良好的收率和优 秀的对映选择性转化为多种不同官能团化的手性四氢 喹啉衍生物. 而 $\beta, \gamma$-不饱和酮在手性伯胺 $\mathbf{A} 7$ 催化下形 成二烯胺中间体与金属铱活化的乙烯基氨基醇发生不 对称 $[4+2]$ 环加成反应, 通过改变铱配体的绝对构型, 能以良好的收率、优秀的立体选择性实现四氢喹啉 45 的非对映选择性发散合成(Scheme 13).

作者认为乙烯基氨基醇与醛的不对称 $[4+2]$ 环加成 反应机理为: 首先, 金属铱络合物活化乙烯基氨基醇生

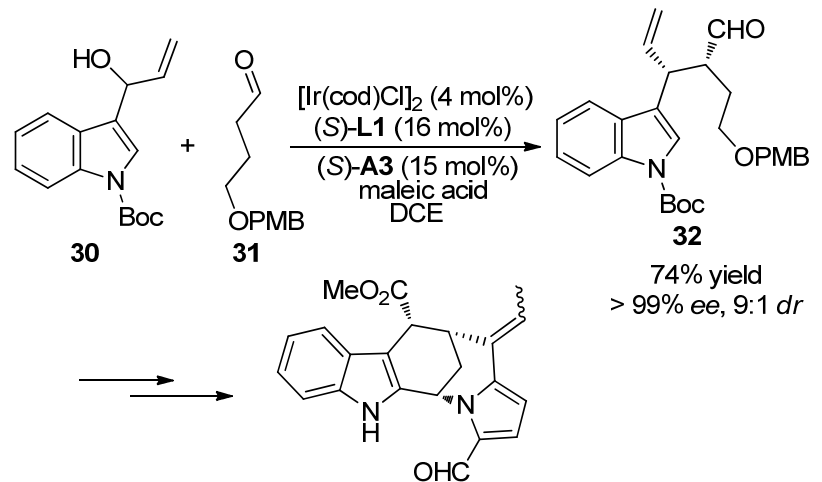

(-)-Alstoscholarine

图式 11 (-)-Alstoscholarine 的全合成

Scheme 11 Total synthesis of (-)-Alstoscholarine
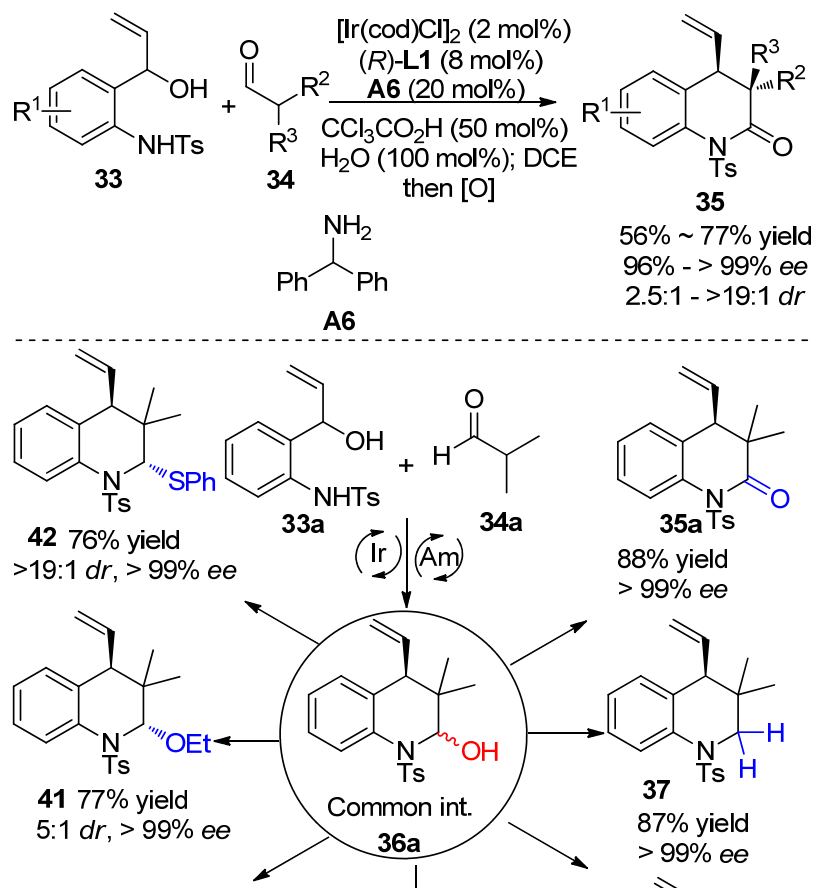<smiles>C=CC1c2ccccc2N([As])C(N)C1(C)C</smiles>

40

$84 \%$ yield $4: 1 d r,>99 \%$ ee

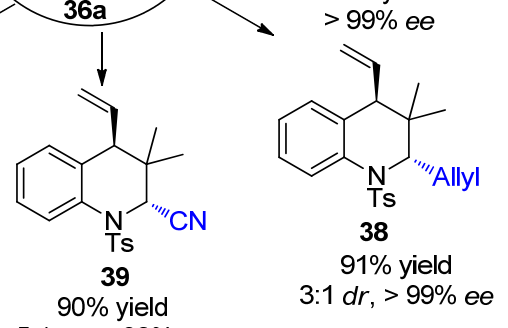

$5: 1 d r,>99 \%$ ee
图式 12 乙烯基氨基醇和醛类化合物的不对称[4+2]环加成 反应

Scheme 12 Asymmetric [4+2] cycloadditions of vinyl aminoalcohols and aldehydes

成 $\pi$-烯丙基铱金属中间体 46, 与此同时醛与伯胺催化 剂结合生成烯胺活性中间体 47. 中间体 46 和中间体 47 之间发生不对称烯丙基取代反应得到中间体 48, 然后 48 经过分子内环化、水解得到半缩醛中间体 39, 随后通 过一系列的转化得到各种取代的二氢喹啉酮和四氢喹 啉化合物(Scheme 14). 


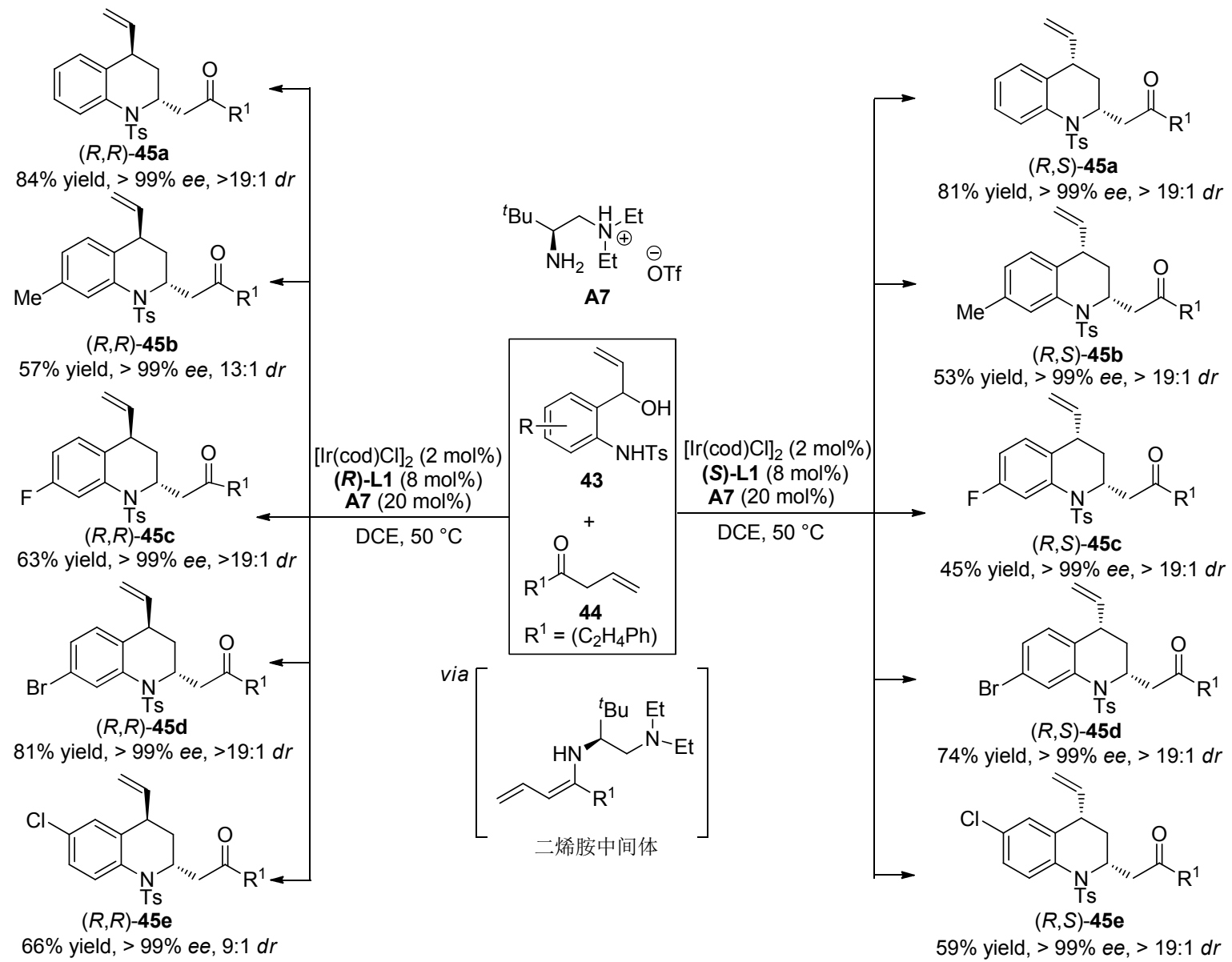

图式 13 乙烯基氨基醇和醛或 $\beta, \gamma$-不饱和酮的不对称 $[4+2]$ 环加成反应

Scheme 13 Asymmetric [4+2] cycloadditions of vinyl aminoalcohols and aldehydes or $\beta, \gamma$-unsaturated ketones

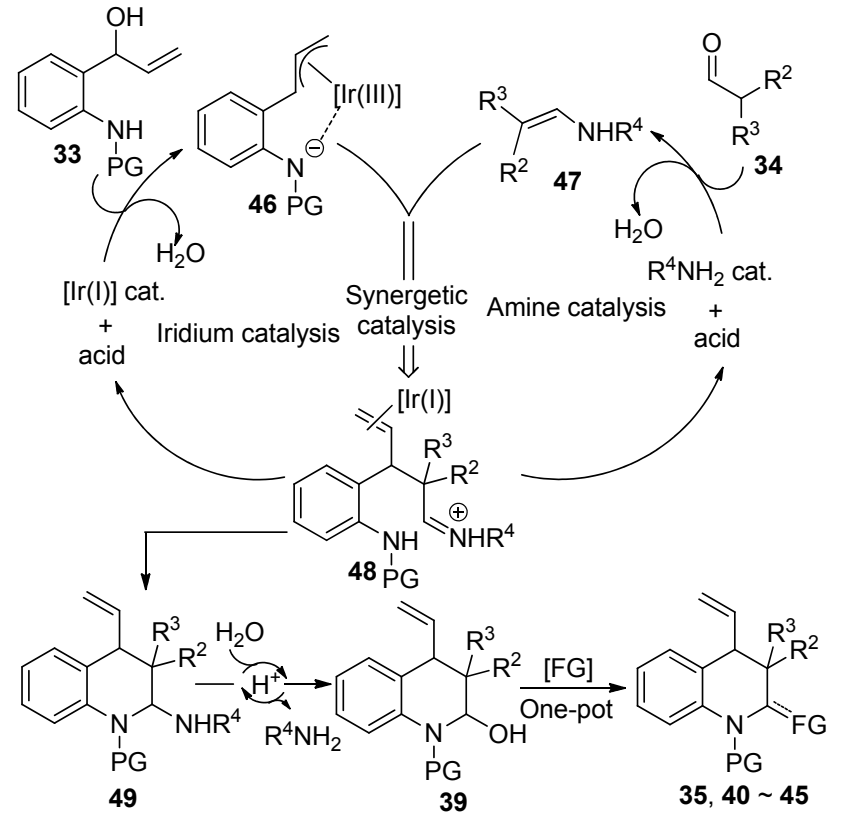

图式 14 铱/胺催化剂协同催化对映选择性合成氢化喹啉化合 物的机理

Scheme 14 Proposed mechanism of synergetic iridium/amine catalysis for the enantioconvergent synthesis of hydroquinolines
与伯胺或仲胺催化剂的活化模式不同，叔胺催化剂 作为一类具有弱亲核性的 Lewis 碱, 常被应用于活化 Morita-Baylis-Hillman (MBH) 碳酸酯, 实现不对称官能 才化反应 ${ }^{[81-83]}$. 2019 年, 陈应春课题组 ${ }^{[84]}$ 利用金属铱与 叔胺协同催化策略，实现了靛红衍生的 $\mathrm{MBH}$ 碳酸酯与 烯丙基碳酸酯的不对称 $[4+3]$ 环化反应. 该反应的实现 需要克服以下挑战: (1)亲核性的叔胺可作为过渡金属的 配体，因此叔胺催化剂与过渡金属催化剂存在兼容性问 题. (2)两类底物均具有烯丙醇结构模块, 要实现叔胺高 化学选择性地活化 $\mathrm{MBH}$ 衍生物, 而过渡金属高化学选 择性地活化另外一个底物是具有挑战的. (3)所产生的两 类偶极中间体均具有较高的反应活性, 这可能会存在较 为严重的背景反应. 通过系统性的条件优化, 作者发现 叔胺 1,4-二氮杂二环[2.2.2]辛烷(DABCO)与预制备的金 属铱/配体络合物组成的协同催化体系, 能够催化目标 反应的发生, 以良好的收率、优秀的立体选择性合成了 一系列吲哚酮螺氮杂草化合物(Scheme 15).

此外，作者利用类似的叔胺与铱络合物协同催化策 略, 成功实现了靛红衍生的 $\mathrm{MBH}$ 碳酸酯与乙烯基氮杂 


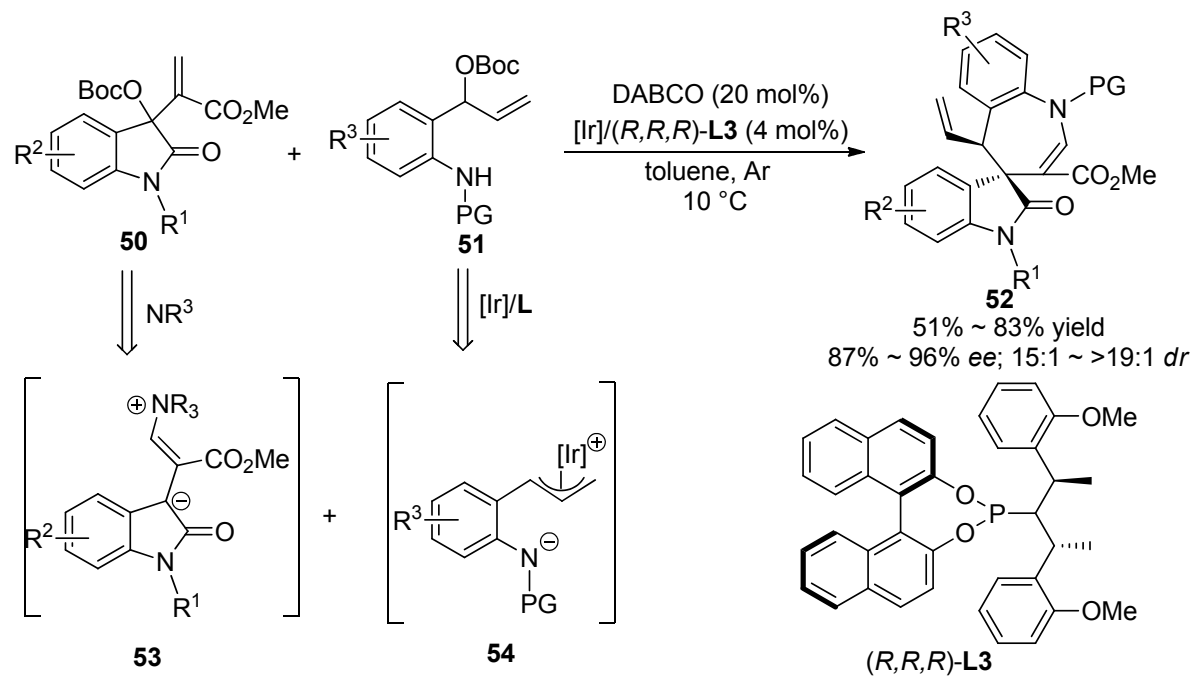

图式 15 铱/三级胺协同催化不对称 $[4+3]$ 环化反应

Scheme 15 Synergetic iridium/tertiary amine catalysis for the asymmetric $[4+3]$ annulations

环丙烷的不对称 $[3+3]$ 环化反应. 该反应具有较为广泛 的底物适用范围, 各种取代的靛红 MBH 碳酸酯均能以 良好的收率、优异的立体选择性得到吲哚酮螺哌啶衍生 物(Scheme 16).

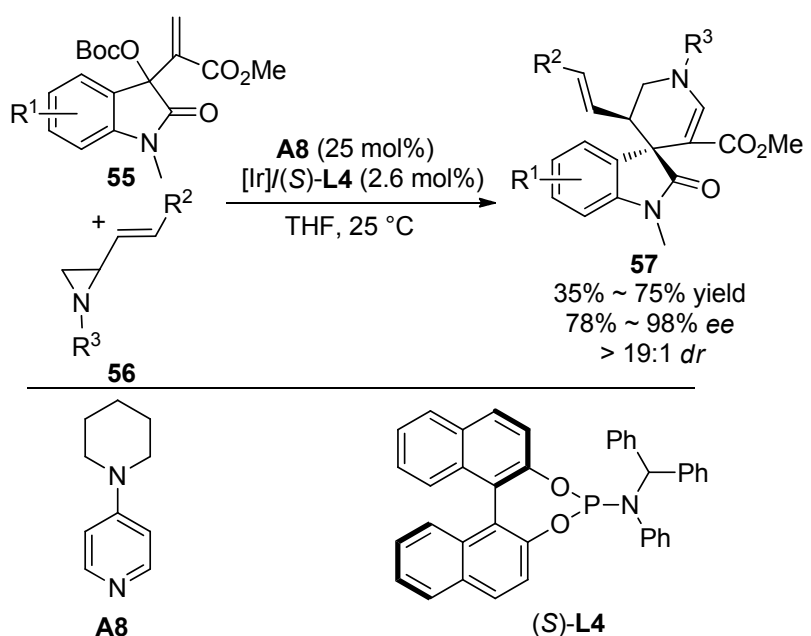

图式 16 铱/三级胺协同催化不对称 $[3+3]$ 环化反应

Scheme 16 Synergetic iridium/tertiary amine catalysis for the asymmetric $[3+3]$ annulations

2020 年, 陈应春课题组 ${ }^{[85]}$ 再次利用叔胺与金属铱 协同催化策略, 实现了靛红衍生的 $\mathrm{MBH}$ 碳酸酯与烯丙 基羧酸酯的不对称 1,3-氧烯丙基化/Cope 重排反应，并 以良好的收率、优秀的对映选择性获得一系列含四取代 烯烃结构的目标化合物(Scheme 17). 此外, 作者通过选 择不同类型的手性铱络合物及对底物的微小调整, 实现 对目标产物的所有异构体(烯烃 $E / Z$ 构型改变和中心手 性改变)的立体发散性合成(Scheme 18).

通过控制实验，作者认为可能的机理为：首先, $\mathrm{DABCO}$ 和手性铱络合物分别活化 $\mathrm{MBH}$ 碳酸酯和烯丙

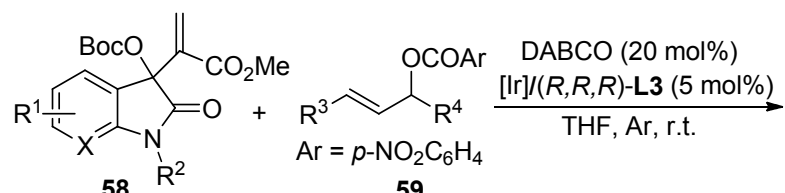

59
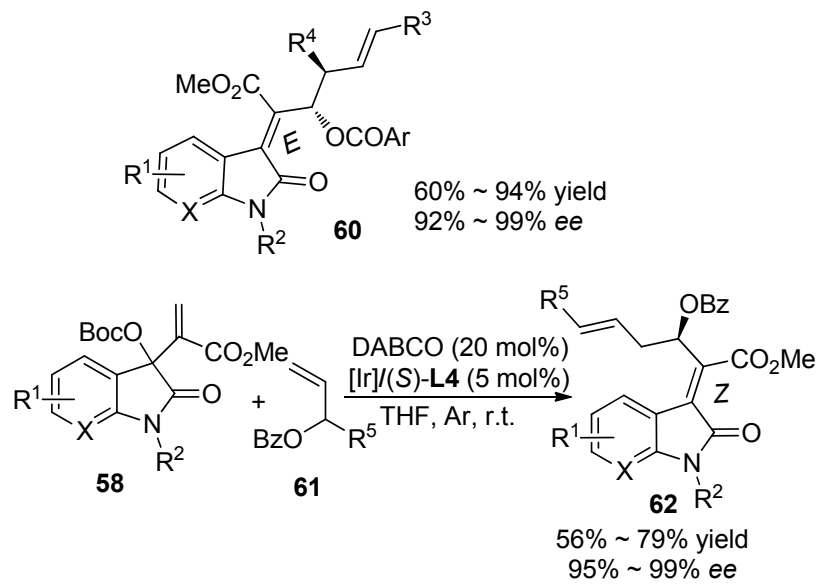

图式 17 铱/三级胺协同催化: 不对称 1,3-氧烯丙基化/Cope 重 排串联反应

Scheme 17 Synergetic iridium/tertiary amine catalysis: the cascade 1,3-oxo-allylation and Cope rearrangement process

醇酯形成中间体 63 和 64 , 接着通过协同催化过程发生 $\gamma$-区域选择性的烯丙基烷基化反应形成中间体 65 , 该中 间体进一步被苯甲酸根负离子进攻，进而消除 $\mathrm{DABCO}$ 生成了 1,3-氧烯丙基化产物. 在这步反应中产生的非对 映选择性导致接下来协同 Cope 重排过程控制 $Z$-式和 $E$ 式两种异构体的生成(Scheme 19).

\section{2 金属铱与相转移催化剂协同催化}

相转移催化剂(PTC)是指可以帮助反应物从一相转 移到能够发生反应的另外一相中，从而加快异相系统反 


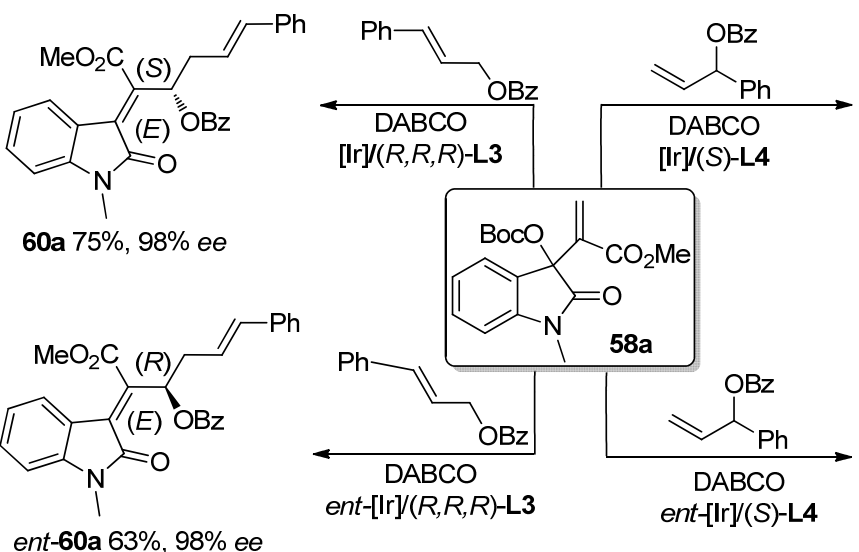

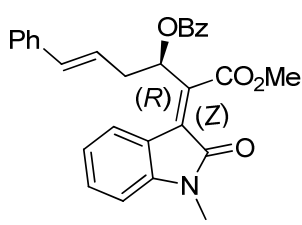

62a $73 \%, 97 \%$ ee

$\mathrm{Ph}$<smiles>C/C=C/C[C@H](OC(C)(C)C)C(C(=O)OC)=C(C(=O)OC)c1ccccc1NC</smiles>

ent-62a $75 \%$, 98\% ee

图式 18 四取代烯烃的四种立体异构体的发散性合成

Scheme 18 Stereodivergent preparation of all stereoisomers of tetrasubstituted alkenes
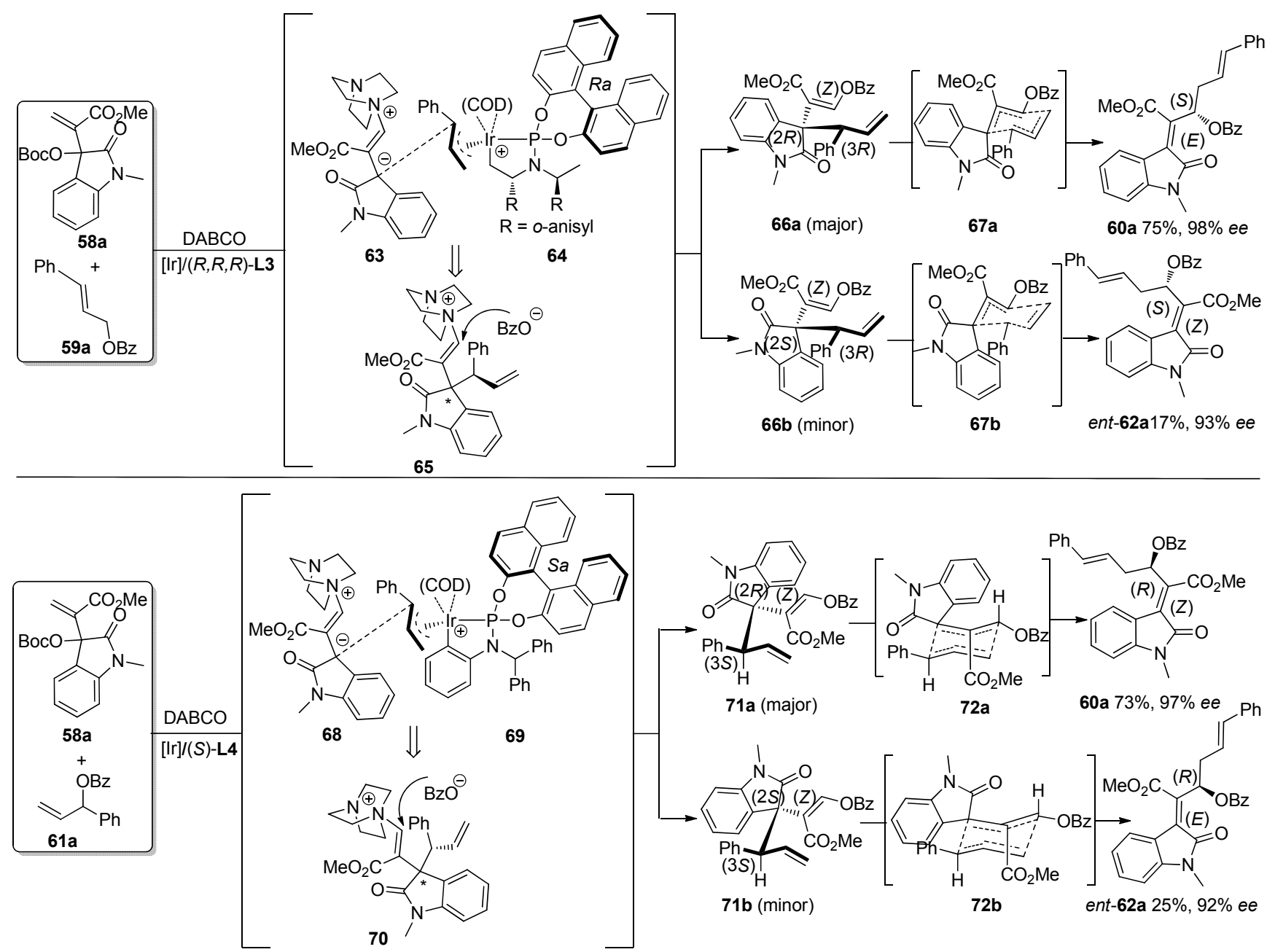

图式 19 不对称 1,3-氧烯丙基化/Cope 重排串联反应的机理研究

Scheme 19 Mechanism study for the cascade 1,3-oxo-allylation and Cope rearrangement process

应速率的一类催化剂，目前已经广泛应用于多种不同类 型的有机反应中 ${ }^{[86]}$.

2001 年, 龚流柱课题组 ${ }^{[87]}$ 和 Takemoto 课题组 ${ }^{[88}$ 通 过使用非手性钯催化剂与手性相转移催化剂组成的协 同催化体系, 实现了甘氨酸酯席夫碱的不对称烯丙基取
代反应. 这是第一例过渡金属与有机小分子协同催化不 对称反应的报道.

相转移催化剂与金属铱协同催化的不对称烯丙基 取代反应由 Takemoto 课题组 ${ }^{[89]}$ 在 2003 年报道, 在甘氨 酸酯席夫碱与支链烯丙基醋酸酯的反应中，作者首次尝 
试了 PTC 与铱组成的协同催化体系, 虽然反应的对映 选择性和非对映选择性均不够理想, 但是这一初步结果 也证实了该协同催化模式的可行性(Scheme 20).

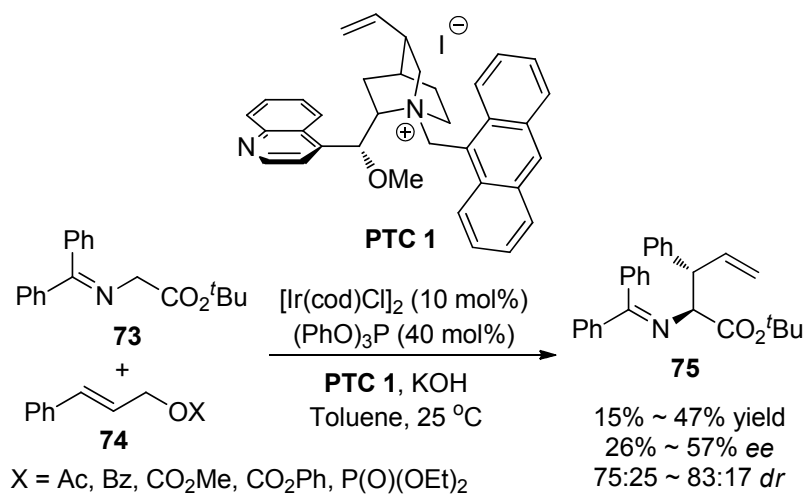

图式 20 铱/相转移协同催化体系: $\beta$-取代的 $\alpha$-氨基酸的合成 Scheme 20 Synergetic Ir/PTC catalysis: synthesis of $\beta$-substituted $\alpha$-amino acids

2013 年, Carreira 课题组报道了支链烯丙醇的不对 称烯基化 ${ }^{[90]}$ 与炔基化 ${ }^{[91]}$ 反应. 此反应表现出了很高的 区域选择性和立体选择性，催化剂对水和空气稳定，易 于操作，适用于芳基或者杂环芳基烯丙醇. 相转移催化 剂 ${ }^{n} \mathrm{Bu}_{4} \mathrm{NHSO}_{4}$ 和 ${ }^{n} \mathrm{Bu}_{4} \mathrm{NBr}$ 的使用有效地解决了烯基三 氟硼酸钾和炔基三氟嗍酸钾在有机溶剂中溶解性不佳 的问题(Scheme 21).

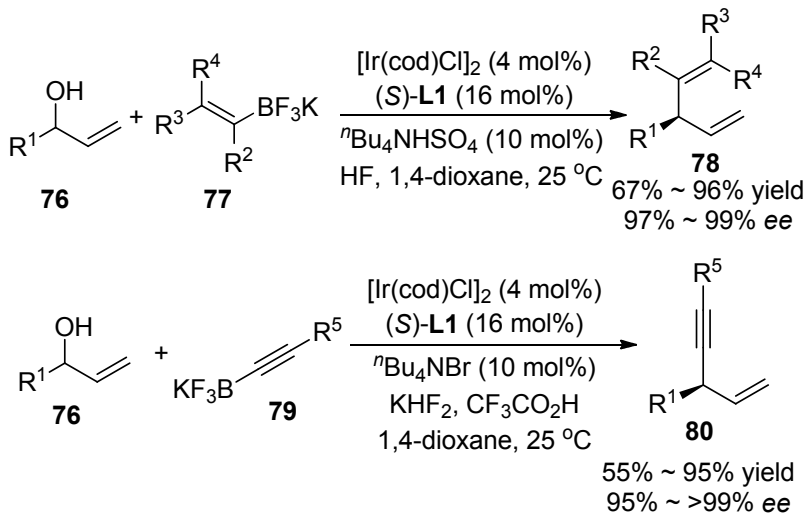

图式 21 铱/相转移协同催化体系: 烯丙醇与烯基三氟嗍酸钾 及炔基三氟嗍酸钾的不对称取代反应

Scheme 21 Synergetic Ir/PTC catalysis: enantioselective substitution of allylic alcohols with potassium alkenyltrifluoroborates and alkynyltrifluoroborates

2017 年, 韩志勇等 ${ }^{[92]}$ 利用铱/相转移协同催化体系, 实现了 $\alpha$-亚胺羧酸酯和烯丙基醋酸酯的不对称烯丙基 化反应. 该反应过程中, 亚胺发生了极性反转(由亲电 性变为亲核性), 以优异的产率和立体选择性得到了含 有两相邻手性中心的 $\alpha$-季碳氨基酸衍生物, 通过简单的 衍生反应可以方便地将产物转化为手性氨基酸盐和含 有多个手性中心的 $\alpha$-季碳脯氨酸衍生物(Scheme 22).

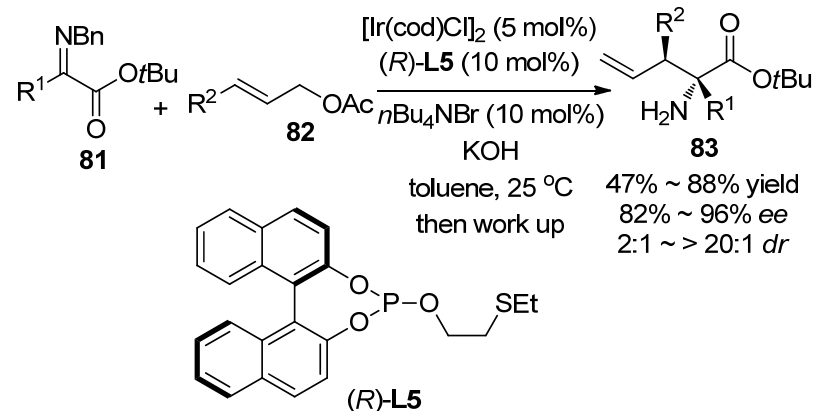

图式 22 铱/相转移协同催化体系: $\alpha$-亚胺羧酸酯的不对称极 性反转烯丙基化

Scheme 22 Synergetic Ir/PTC catalysis: asymmetric umpolung allylation of $\alpha$-imino ester

作者提出了如下反应机理(Scheme 23): 在氢氧化 钾和相转移催化剂 ${ }^{n} \mathrm{Bu}_{4} \mathrm{NBr}$ 作用下, $\alpha$-亚胺羧酸酯 81 去 质子化得到 2-氮杂烯丙基负离子. 同时烯丙基醋酸酯与 金属铱络合物发生氧化加成得到 $\pi$-烯丙基铱中间体 86 . 2 -氮杂烯丙基负离子进攻 $\pi$-烯丙基铱中间体，完成立体 选择性的烯丙基化反应，得到中间体 $\mathbf{8 7}$, 经水解后得到 $\alpha$-季碳氨基酸酯产物 83. 在该反应过程中，立体选择性 主要由手性配体控制, 但相转移催化剂在反应中也起到 重要作用, 不仅对反应收率有重要影响, 还作为 2-氮杂 烯丙基负离子的抗衡阳离子影响烯丙基化反应过程，进 而提高反应的立体选择性.

2017 年, Hartwig 课题组 ${ }^{[93]}$ 报道了预制备的铱与手 性配体的络合物与相转移催化剂协同催化的不对称烯 丙基取代反应(Scheme 24). 作者用 $3 \sim 4 \mathrm{~mol} \%$ 的 ${ }^{n} \mathrm{Bu}_{4} \mathrm{NOBz}$ 作相转移催化剂, 实现了肉桂醇羧酸酯与硅 烷基烯酮缩醛的取代反应，以优秀的收率和立体选择性 得到了脂肪烃取代的羧酸酯, 产物在温和的条件下就能 转化为伯醇、羧酸、酰胺等衍生物. 在此反应中, 相转 移催化剂的存在至关重要, 缺少相转移催化剂反应将完 全无法进行.

2020 年, 王春江课题组 ${ }^{[94]}$ 在报道了铱/铜协同催化 的不对称烯丙基取代与 2-氮杂-Cope 重排串联反应后, 巧妙地用相转移催化剂 ${ }^{n} \mathrm{Bu}_{4} \mathrm{NBr}$ 替代传统的铜催化剂, 对 $\alpha$ 位含大位阻基团的席夫碱活化，得到了与铱/铜双金 属体系相当的反应结果，合成了一系列手性高烯丙基胺 衍生物. 该金属铱与相转移协同催化体系相较于双金属 催化体系更为绿色环保且操作简单，但反应对席夫碱底 物的邻位取代基仅报道了 ${ }^{i} \mathrm{Bu}$ ，且产物取代基的多样性 略逊于双金属体系(Scheme 25).

相转移催化剂的运用，使得铱催化的不对称烯丙基 取代反应得以在非均相体系中顺利进行, 推动了铱催化 的不对称烯丙基取代的进一步发展. 然而目前相关研究 主要集中于非手性的相转移催化剂, 手性相转移催化剂 


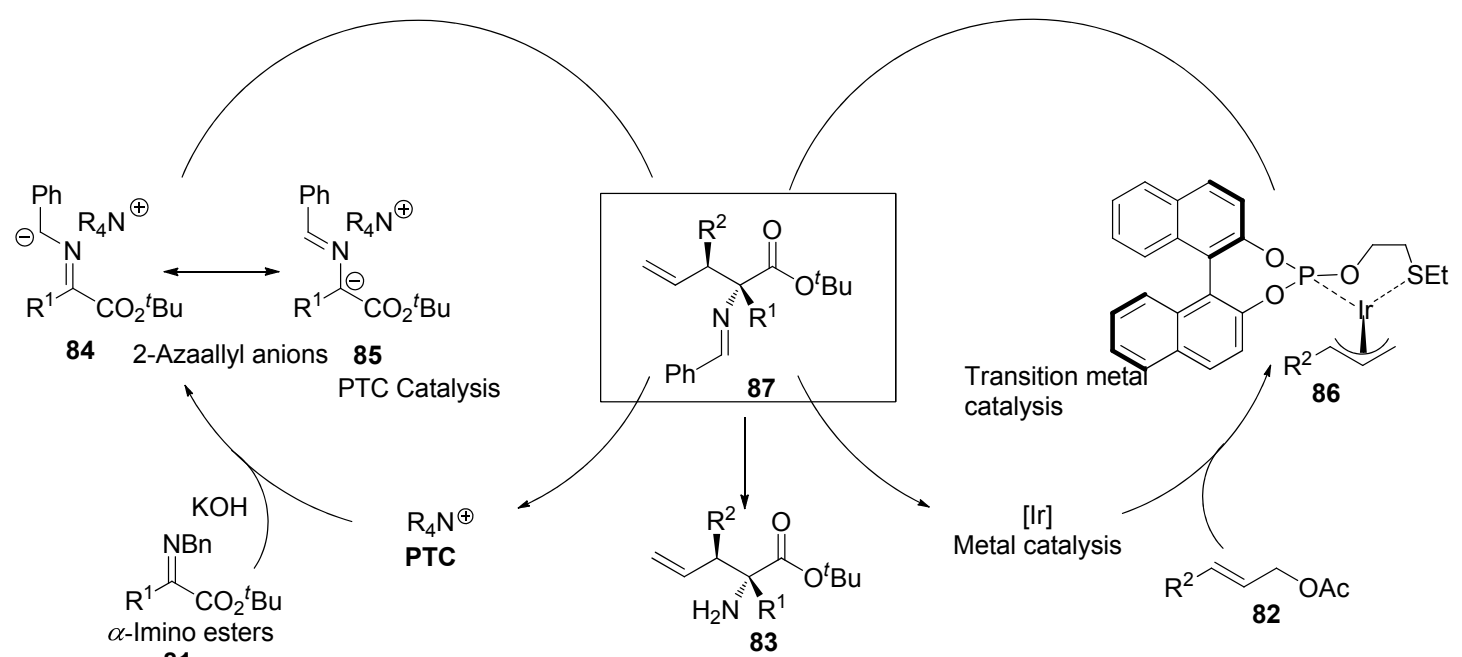

81

图式 23 铱/相转移协同催化 $\alpha$-亚胺羧酸酯的不对称烯丙基取代中可能的机理

Scheme 23 Proposed mechanism of Ir/PTC synergetic catalyzed asymmetric allylation of $\alpha$-imino ester

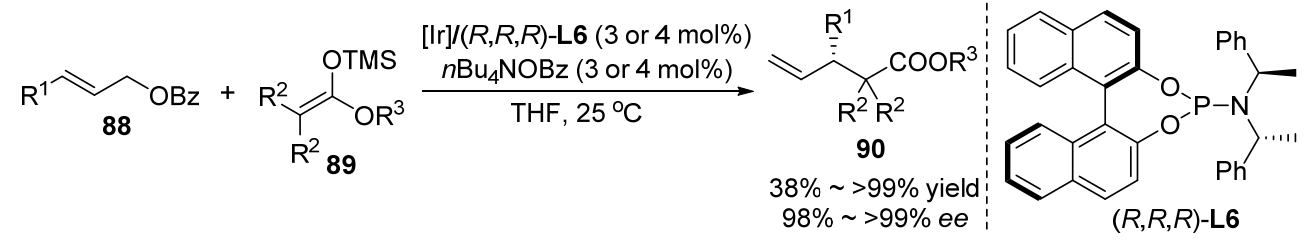

图式 24 铱/相转移协同催化体系: 硅烷基烯酮缩醛的不对称烯丙基取代

Scheme 24 Synergetic Ir/PTC catalysis: enantioselective allylic substitution of silyl ketene acetals

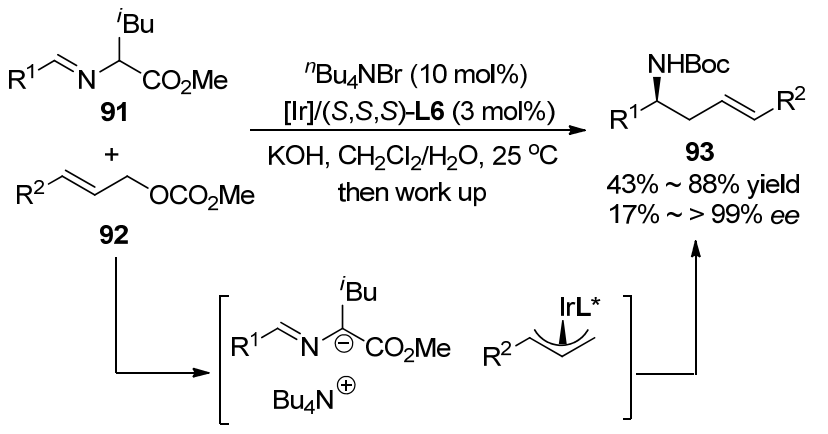

图式 25 铱/相转移协同催化体系: 亚甲胺叶立德参与的烯丙 基化/2-氮杂-Cope 重排反应

Scheme 25 Synergetic Ir/PTC catalysis: allylic alkylation/ 2-aza-Cope rearrangement of azomethine ylides

在此体系中的应用并不理想，两种催化剂间的手性匹配 问题仍然有待深入研究.

\section{3 金属铱与布朗斯特酸协同催化}

2004 年, Akiyama 课题组 ${ }^{[95]}$ 和 Terada 课题组 ${ }^{[96]}$ 分别 独立报道了联菜酚骨架的手性磷酸催化的不对称 Mannich 反应, 由此拉开了手性布朗斯特酸催化不对称 反应研究的序幕. 通常, 布朗斯特酸催化有机反应是通 过质子化作用形成离子对或者氢键, 也可以用作双功能 催化剂. 手性磷酸作为布朗斯特酸的重要组成部分, 具
有种类众多、结构可调节性大等特点. 手性磷酸与金属 铱协同催化结合了两类催化剂的优点, 为铱催化的不对 称烯丙基取代反应提供了新的途径.

2017 年, 钟国富课题组 ${ }^{[97]}$ 利用手性铱络合物与磷 酸协同催化体系, 实现了 2-荎酚的不对称烯丙基取代去 芳构化反应(Scheme 26). 该反应以简便易得的支链烯 丙醇为底物, 以良好的收率和优秀的对映选择性合成了 一系列手性 $\beta$-䒬酮衍生物. 控制实验结果表明, 手性铱 络合物对反应的立体诱导起到关键作用, 而添加磷酸有 助于烯丙醇脱水以降低反应能垒, 并且在立体控制步骤 中大位阻的磷酸有助于提高反应的对映选择性.

结合控制实验和文献，作者提出了如下可能的机理 (Scheme 27): 烯丙醇底物在手性铱络合物和布朗斯特 酸共同作用下, 失去一分子的水, 生成 $\pi$-烯丙基铱中间 体 97, 此时布朗斯特酸脱去质子成为相应的共轭碱. 此 共轭碱与荎酚羟基的氢原子产生氢键作用, 弱化了氢氧 键，活化的萗酚与中间体 97 络合产生了关键中间体 $\mathbf{9 8}$. 随后发生分子内亲核加成得到目标产物，同时脱去铱络 合物和磷酸完成催化循环. 在这个催化循环中, 大空间 位阻的磷酸与手性铱络合物协同作用显著提高了反应 的对映选择性，而手性与消旋的磷酸在反应中都能得到 优异的产率和对映选择性，使用消旋配体衍生的金属铱 
络合物与手性磷酸组成的协同催化体系则只能得到消 旋的产物. 这表明手性铱络合物对产物的对映选择性控 制起到决定作用.
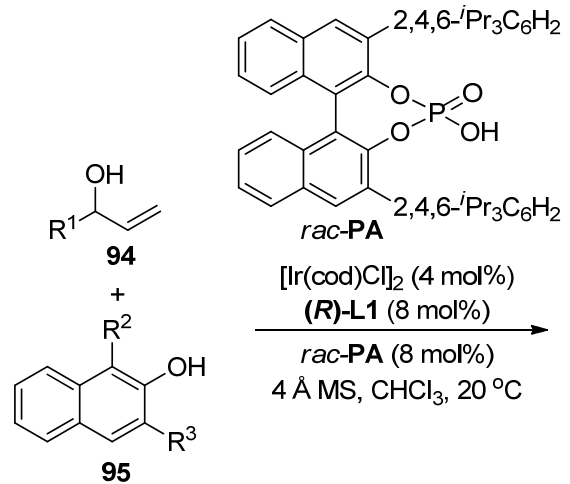

$4 \AA \mathrm{MS}, \mathrm{CHCl}_{3}, 20^{\circ} \mathrm{C}$

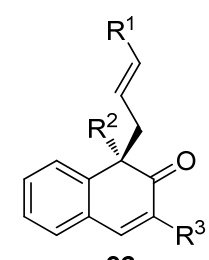

96 $51 \% \sim 87 \%$ yield $79 \%$ > $99 \%$ ee
图式 26 铱/磷酸协同催化体系: 菜酚衍生物和烯丙基醇的不 对称烯丙基去芳构反应

Scheme 26 Synergetic Ir/phosphoric catalysis: the asymmetric allylic dearomatization of naphthols with secondary allylic alcohols

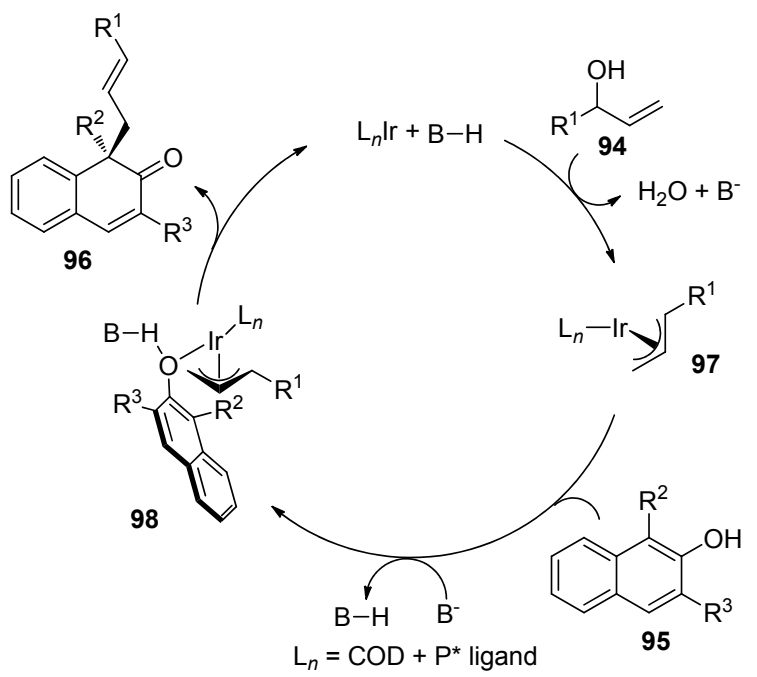

图式 27 萗酚衍生物和烯丙基醇的不对称烯丙基去芳构反应 机理

Scheme 27 A proposed mechanism of the asymmetric allylic dearomatization reaction of naphthols with secondary allylic alcohols

\section{4 金属铱与路易斯碱协同催化}

路易斯碱是指在反应中能提供电子云的分子或者 原子团，包括有机磷、卡宾、三级胺等，在催化反应时 往往对底物进行亲核进攻生成鏻盐和铵盐、烯醇负离子 等活泼中间体.

2003 年, Krische 课题组 ${ }^{[98]}$ 报道的三叔丁基膦作为 路易斯碱与四三苯基膦钯协同催化的分子内烯丙基取 代反应是最早关于路易斯碱与过渡金属协同催化的报 道，但文中并没有涉及到不对称诱导效应的研究.
金属铱与路易斯碱协同催化的不对称烯丙基取代 反应于 2017 年才开始被逐渐报道, 其中已经被证明能 与金属铱兼容并实现协同催化的路易斯碱有三类: 异硫 嫝类催化剂、氮杂卡宾催化剂以及在第二部分中介绍过 的叔胺催化剂.

异硫艮类催化剂于 20 世纪初由 Birman 课题组 ${ }^{[99]}$ 设计合成, 最初适用于催化醇的不对称动力学拆分反 应. 2008 年, Romo 课题组 ${ }^{[100]}$ 首次将异硫服类催化剂应 用于烯胺醇负离子中间体的生成中, 实现了酮酸的不对 称分子内环化反应，大大地拓展了这类催化剂的应用范 围. 2016 年, Snaddon 课题组 ${ }^{[101]}$ 实现了金属钯催化剂与 异硫嫝催化剂协同催化的芳基乙酸酯的不对称 $\alpha$ 位苄基 化反应，这是过渡金属与该类催化剂协同催化的首例成 功报道.

2017 年, Hartwig 课题组 ${ }^{[102]}$ 实现了金属铱与异硫嫝 催化剂协同催化芳基乙酸酯的不对称支链烯丙基取代 反应(Scheme 28). 在反应中, 当异硫艮类催化剂(BTM) 作为路易斯碱与铱的亚磷酰胺配体络合物协同作用，可 以以优秀的立体选择性得到目标产物，同时改变两种催 化剂的立体构型，可以成功得到所有立体构型的产物. 需要指出的是, 五氟苯基酯与叔丁氧羰基酯都是该反应 的关键，其他的芳基衍生物与离去基团都会显著降低产 率和立体选择性.

氮杂环卡宾是一类重要的路易斯碱催化剂, 它催化 的有机反应具有操作简单、选择性好、无污染等优点而 引起了化学家们的广泛关注. 但是由于其较强的亲核 性，可作为配体与过渡金属形成稳定的金属配合物，容 易降低过渡金属催化剂活性，这一性质在一定程度上阻 碍了过渡金属与氮杂环卡宾协同催化反应的发展. 2016 年, 游书力课题组 ${ }^{[103]}$ 报道了氮杂环卡宾作为手性配体 在金属铱催化分子内不对称烯丙基取代反应中的应用, 作者通过单晶 $\mathrm{X}$ 射线衍射证实了氮杂环卡宾与金属铱 络合物的存在，并证明了其催化活性.

2019 年, Glorius 课题组 ${ }^{[104]}$ 报道了金属铱与氮杂环 卡宾协同催化的不对称烯丙基取代环化反应(Scheme 29), 证实了这两种催化剂的兼容性与匹配性. 作者从 烯丙基环碳酸酯 104 和 106 出发, 与肉桂醛衍生物及 $\alpha$ 氯代醛以优秀的收率和立体选择性得到了环化产物. 但 在对其进行发散性合成时，作者发现原先的体系并不能 得到良好的结果，通过对条件的再次筛选，作者发现氮 杂卡宾催化剂 $\mathbf{N} 2$ 更有利于发散合成，但是对于反式内 酯的产物也未能得到与顺式内酯相当的非对映选择性. 为了克服这一缺点，作者利用反式异构体在热力学和动 力学上更受青睐的特点, 通过二异丙基氨基锂(LDA)处 理顺式产物 $(R, S)-\mathbf{1 0 5} \mathbf{a}$, 成功地得到了具有高非对映选 
择性的反式内酯 $(S, S)-\mathbf{1 0 5} \mathbf{a}$, 为合成具有高非对映选择 性的反式内酯提供了一条替代路线.
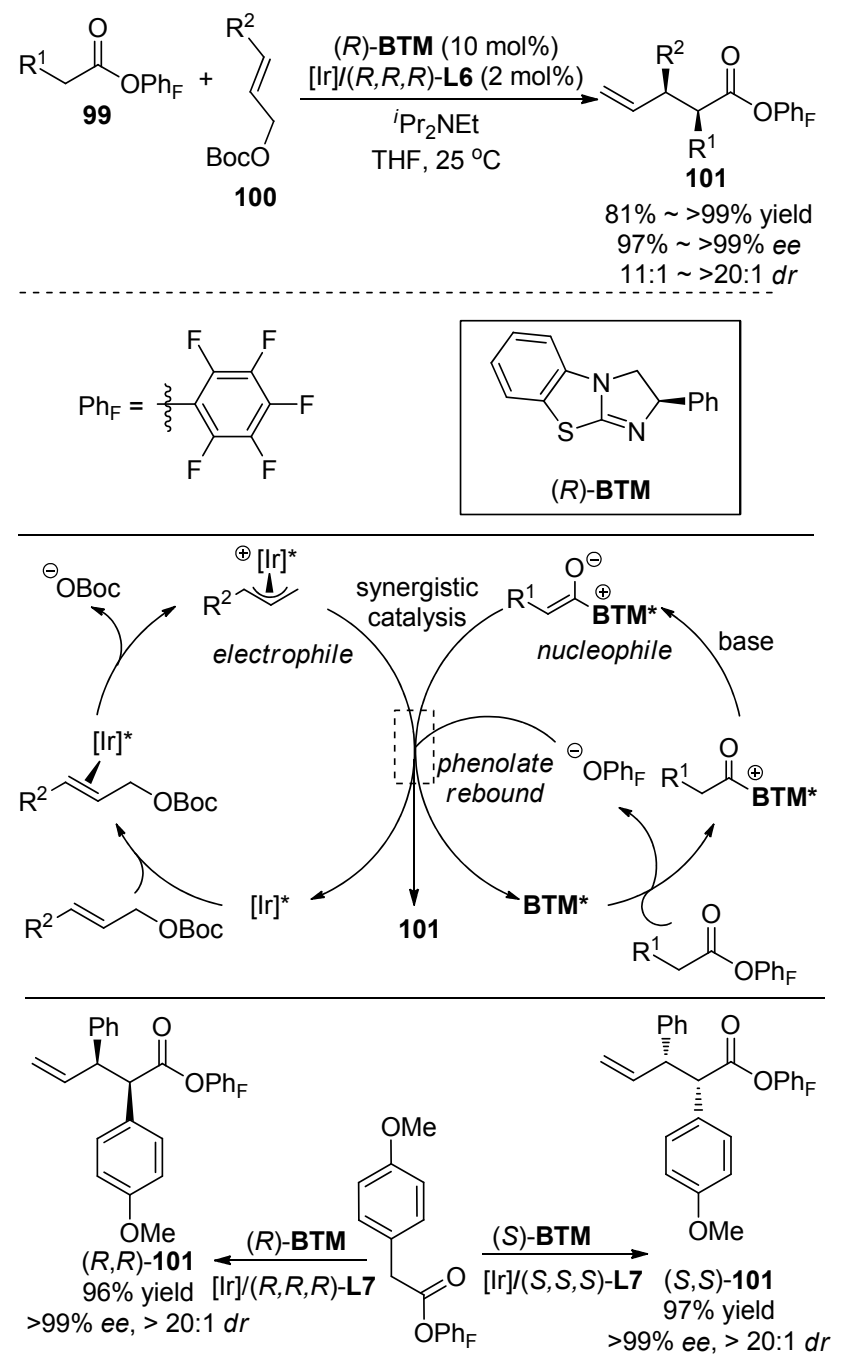

$$
\begin{aligned}
& \overbrace{\mathrm{OPh}_{F}}^{\mathrm{Ph}}
\end{aligned}
$$

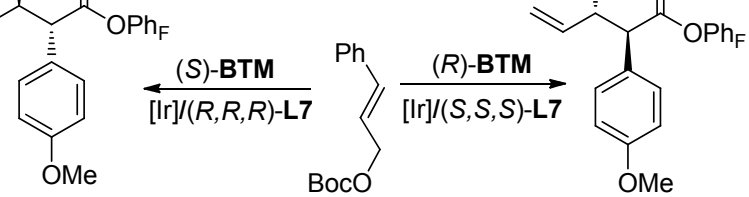

$$
\begin{aligned}
& (S, R)-101 \\
& 99 \% \text { yield } \\
& >99 \% \text { ee, }>20: 1 d r
\end{aligned}
$$

图式 28 铱/BTM 协同催化体系: 芳基乙酸酯的不对称烯丙 基化

Scheme 28 Synergetic Ir/BTM catalysis: enantioselective allylations of aryl acetic acid esters

作者提出了如下反应机理(Scheme 30), 氮杂环卡 宾游离后与 $\alpha, \beta$-不饱和酫形成反式烯醇中间体, 然后通 过 $\beta$ 质子化(或者由 $\alpha$ 氯代醛通过碱介导发生氯化物消 除)。卡宾上的取代基屏蔽了烯醇化物中间体的背面. 在金属的催化循环中，碳酸乙烯基亚乙酯在金属铱作用 下形成了 $\pi$-烯丙基铱中间体(该中间体可以通过质谱捕
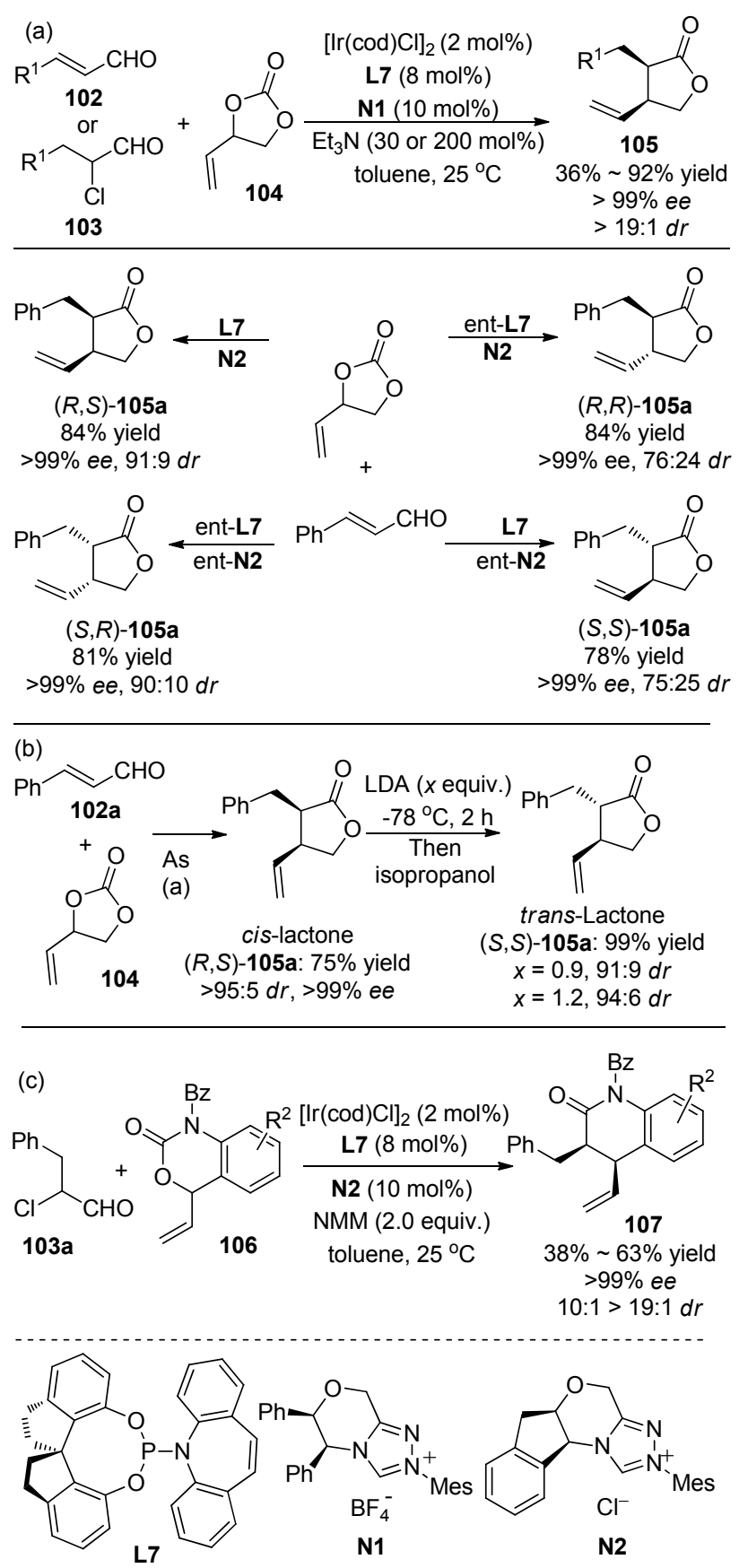

图式 29 铱/氮杂环卡宾协同催化体系: 不对称 $[3+2]$ 和 $[4+$ 2]环加成反应

Scheme 29 Synergetic Ir/NHC catalysis: asymmetric [3+2] and $[4+2]$ cycloadditions

获得到)，理论计算表明，中间体的背面被屏蔽. 最后烯 醇中间体的 $S i$ 面与 $\pi$-烯丙基铱中间体的 $S i$ 面靠近, 发 生分子间烯丙基取代反应，然后经过内酯化得到产物, 并游离出催化剂完成催化循环.

\section{5 金属铱与其他过渡金属协同催化}

除了上述介绍的金属铱与有机小分子催化剂协同 


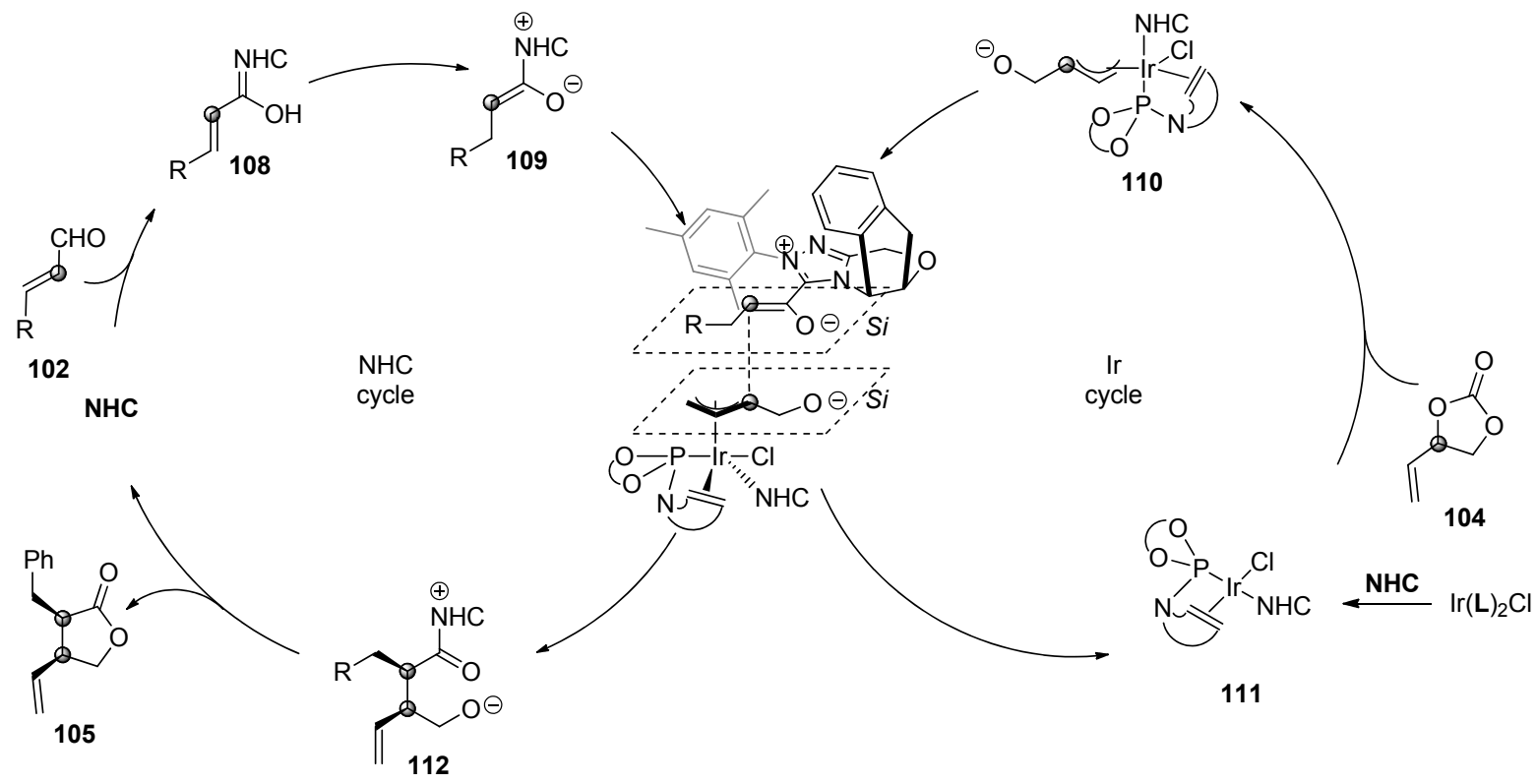

图式 30 协同的铱/氮杂环卡宾催化: 不对称 $[3+2]$ 环加成反应机理

Scheme 30 Synergetic Ir/NHC catalysis: a proposed mechanism of asymmetric [3+2] cycloadditions

催化的不对称烯丙基取代反应外，金属铱与其他过渡金 属协同催化的不对称烯丙基取代反应在最近几年也取 得了重要进展，另一种过渡金属的引入大大拓展了亲核 试剂的范围，同时通过调整手性配体的构型也可以实现 立体发散性合成.

2016 年, 张万斌课题组 ${ }^{[105]}$ 报道了在温和条件下, 铱/锌双金属协同催化的 $\alpha$-差基酮的 $\alpha$-烯丙基化反应 (Scheme 31). 衍生于亚磷酰胺配体的手性铱络合物和 手性 Zn-Pro 苯酚络合物的协同作用，使反应具有很高 的活性和优秀的对映选择性及非对映选择性, 反应的关 键中间体就是锌与 $\alpha$-羟基苯乙酮形成的五元环过渡态. 该反应通过不同绝对构型配体的组合可以得到四种立 体异构体，实现立体发散性合成.

2017 年, 张万斌课题组 ${ }^{[106]}$ 又采用同样的体系实现 了非保护的 $\alpha$-羟基茚酮的 $\alpha$-烯丙基化反应(Scheme 32). 该反应克服了 $\alpha$-羟基茚酮反应位点多、立体位阻大和烯 醇化困难等困难, 在温和条件下高效、高立体选择性地 得到具有连续三取代/四取代手性中心的环状 $\alpha$-差基狮 酮衍生物, 并成功实现了产物立体发散性合成.

2018 年, 张万斌课题组 ${ }^{[107]}$ 开发了可用于立体发散 性合成的铱/铜双金属协同催化体系，并将其用于非天 然 $\alpha$-氨基酸的立体选择性合成. 该反应底物适用性广 泛，一系列的烯丙基底物和醛亚胺酯都可以顺利用于该 催化体系, 取得了良好的收率及优秀的对映选择性和非 对映选择性. 此外, 反应产物通过简单的转化即可用于 天冬氨酸类似物的立体发散性合成, 可作为一种谷氨酸 转运体的亚型选择性阻断剂(Scheme 33a). 值得注意的
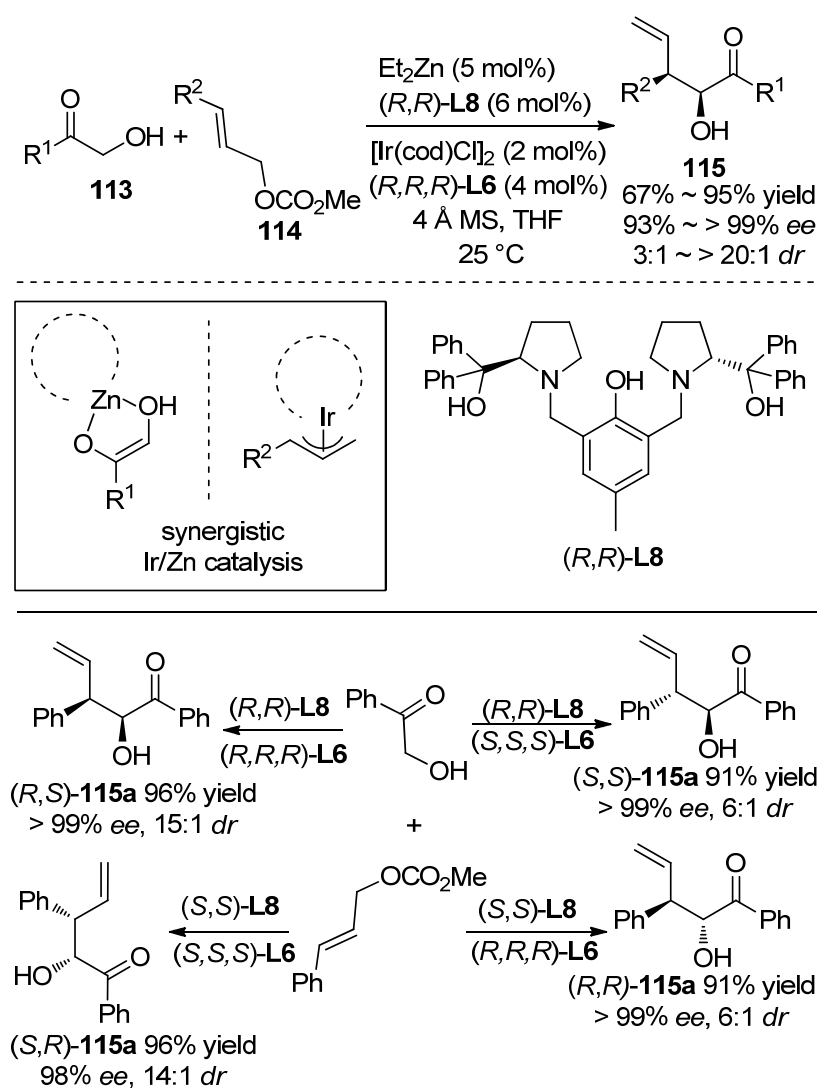

图式 31 铱/锌协同催化: $\alpha$-羊基酮的不对称烯丙基化反应 Scheme 31 Synergetic Ir/Zn catalysis: asymmetric allylation $\alpha$-allylation of $\alpha$-hydroxyketones

是，几乎同时，王春江课题组 ${ }^{[108]}$ 报道了类似的铱/铜协 同催化反应(Scheme 33b), 并且也成功地以优秀的收率 和立体选择性构建了邻位双取代氨基酸衍生物, 不同构 


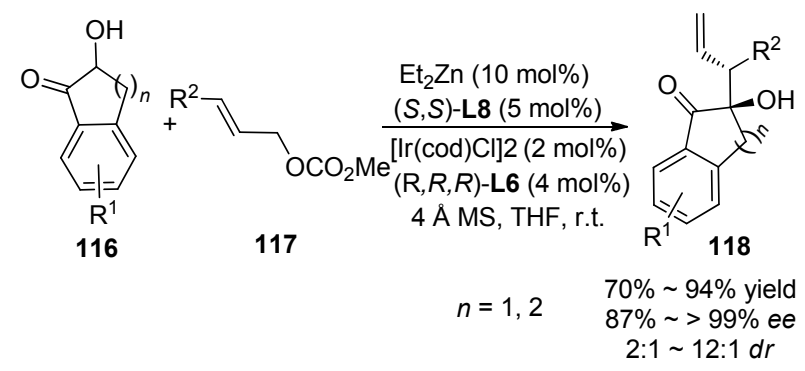

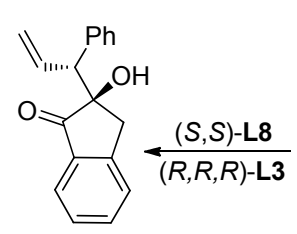

$(R, R)-118$ a $93 \%$ yield 97\% ee, 5:1 dr<smiles>O=C1c2ccccc2CC1O</smiles>

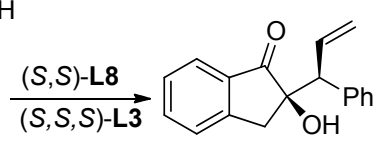

$(R, S)-118$ a $94 \%$ yield $94 \%$ ee, $2: 1 d r$

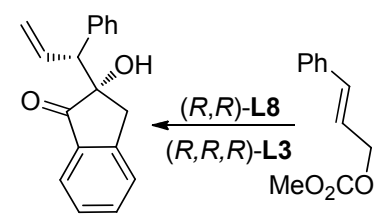

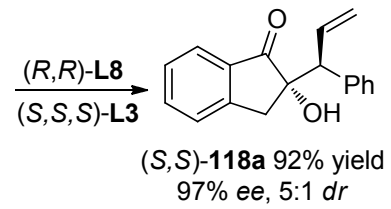

$(S, R)-118$ a $92 \%$ yield $94 \%$ ee, $2: 1 d r$

图式 32 铱/锌协同催化: $\alpha$-羟基狮酮的不对称烯丙基化反应 Scheme 32 Synergetic $\mathrm{Ir} / \mathrm{Zn}$ catalysis: asymmetric allylation $\alpha$-allylation of $\alpha$-hydroxy indanones

型配体的组合也能以优秀的结果得到四种立体异构体. 此外, 两种金属与两种配体同时加入同一容器, 分别配 位再混合得到了相当的结果, 两种活性催化剂可以通过 “金属/配体自分类” 方式获得，简化了操作步骤.

同年，张万斌课题组 ${ }^{[109]}$ 利用相似的铱/铜协同催化 体系, 进一步实现了酮亚胺酯与烯丙基碳酸酯的不对称 取代反应(Scheme 34). 该反应进一步拓展了席夫碱的 范围, 合成了邻位单取代氨基酸衍生物, 通过简单的后 处理即可得到伯胺产物. 此外, 配体改变获得四种立体 异构体的优势在此报道中也得以体现.

2018 年, Hartwig 课题组 ${ }^{[110]}$ 报道了铱/铜协同催化的 氮杂芳基乙酰胺的不对称烯丙基取代反应(Scheme 35), 该反应实现了手性含氮杂芳基化合物的立体发散性合 成, 且反应具有较高的对映选择性和非对映选择性. 各 种含吡啶基、苯并噻唑基、苯并噁唑基、吡嗪基、喹啉 基和异喹啉基的氮芳基乙酰胺都表现出了良好的活性.

2019 年, 王春江课题组 ${ }^{[111]}$ 应用铱/铜协同催化体系, 从简单易得的醛亚胺酯和吲哚基烯丙基碳酸酯出发构 建了含有多手性中心的四氢- $\gamma$-咔啉衍生物. 在该反应 中, 吲哚基烯丙基碳酸酯的烯丙基邻位空间结构较大, 使得传统的 Feringa 类型配体(L3、L6 等)不能取得良好 的结果, 而游书力课题组发展的亚磷酰胺配体 L13, 由 于其与铱配位后在空间上不拥挤, 可以兼容位阻较大的 (a) Zhang's work

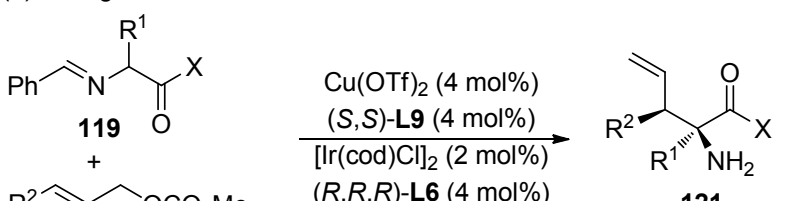

$$
\begin{aligned}
& 121 \\
& \begin{array}{cc}
\mathrm{R}^{2} \mathrm{OCO}_{2} \mathrm{Me} & \begin{array}{c}
(R, R, R)-\mathrm{L} 6(4 \mathrm{~mol} \%) \\
\mathrm{Cs}_{2} \mathrm{CO}_{3}, \mathrm{THF} \\
2 \mathrm{O}^{\circ} \mathrm{C}
\end{array} \\
&
\end{array}
\end{aligned}
$$

(b) Wang's work

(i) $\mathrm{Cu}(\mathrm{MeCN})_{4} \mathrm{BF}_{4}(5 \mathrm{~mol} \%)$ $(R, R)-\mathrm{L} 10(5 \mathrm{~mol} \%)$

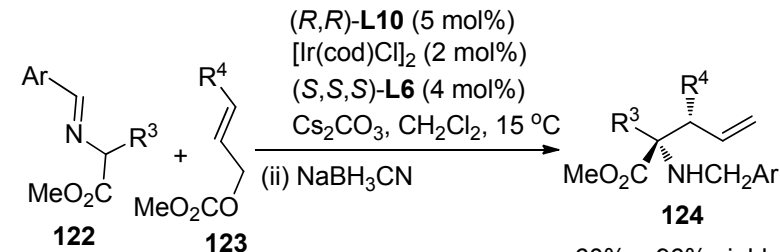
$\mathrm{Ar}=p-\mathrm{Cl}-\mathrm{C}_{6} \mathrm{H}_{4} \quad 123 \quad 60 \% \sim 96 \%$ yield $94 \% \sim>99 \%$ ee $7: 1 \sim>20: 1 d r$

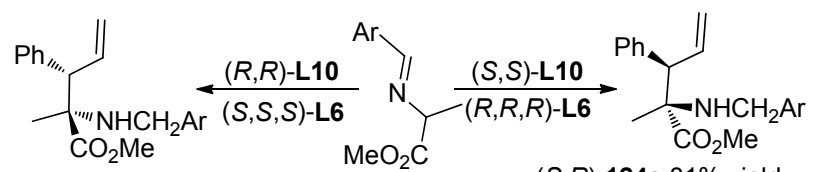
$\begin{array}{cc}(R, S)-124 a \text { 84\% yield } & (S, R)-124 a \text { 81\% yield } \\ 99 \% \text { ee }>20: 1 d r & +\quad\end{array}$

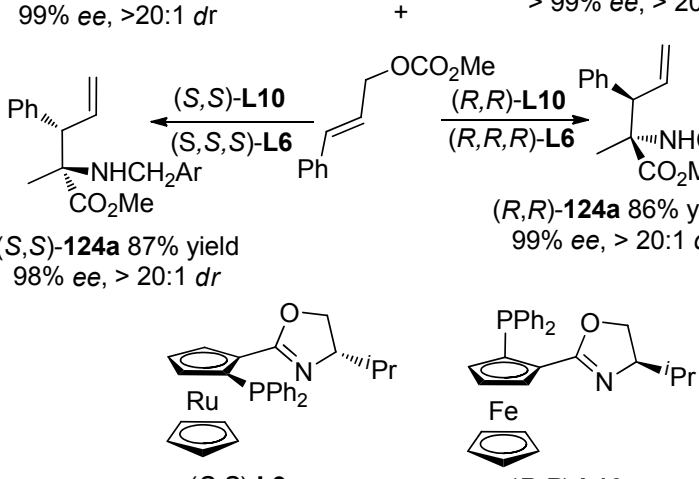

$(S, S)$-L9
图式 33 铱/铜协同催化: 邻位双取代氨基酸的立体发散合成 Scheme 33 Synergetic $\mathrm{Ir} / \mathrm{Cu}$ catalysis: stereodivergent synthesis of $\alpha, \alpha$-disubstituted $\alpha$-amino acids

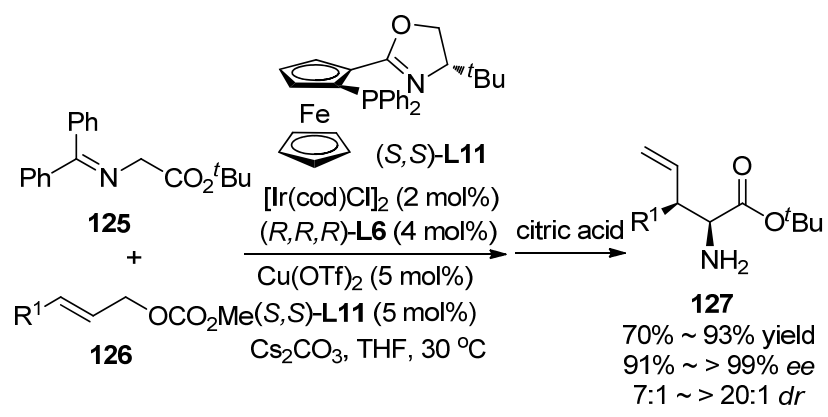

图式 34 铱/铜协同催化: 甘氨酸席夫碱的不对称烯丙基化 Scheme 34 Synergetic $\mathrm{Ir} / \mathrm{Cu}$ catalysis: asymmetric allylation of the glycine-based ketimine esters 


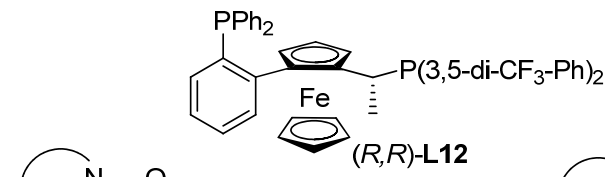
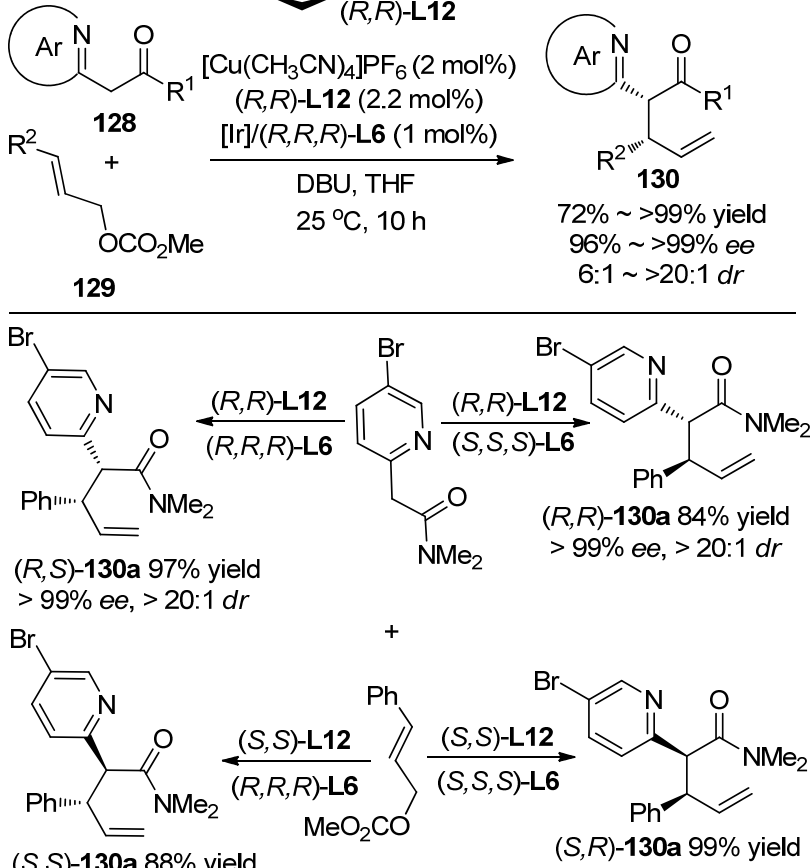

$(S, S)-130$ a $88 \%$ yield

$(S, R)-130$ a $99 \%$ yield $>99 \%$ ee, $>20: 1 d r$

$>99 \%$ ee, $>20: 1 d r$

图式 35 铱/铜协同催化: 氮杂芳基乙酰胺的不对称烯丙基化

Scheme 35 Synergetic $\mathrm{Ir} / \mathrm{Cu}$ catalysis: asymmetric allylation of azaaryl acetamides

底物 ${ }^{[112]}$, 在反应中取得了优秀的立体选择性控制结果. 该体系实现了四氢- $\gamma$-咔啉衍生物的立体发散合成, 通 过改变配体构型可以获得四种光学异构产物. 作者通过 控制实验证实, 立体发散的烯丙基取代反应和随后发生 的立体专一性的 iso-Pictet-Spengler 环化是反应顺利进 行的关键(Scheme 36).

王春江课题组 ${ }^{[13]}$ 在铱/铜协同催化席夫碱的不对称 烯丙基取代反应的研究中发现, 亚甲胺叶立德发生烯丙 基化反应后的产物具有特殊的烯丙基-氮杂烯丙基结构, 巧妙地通过增大亚甲胺叶立德 $\alpha$ 位取代基的位阻, 迫使 中间体通过重排反应得到了更稳定的高烯丙胺衍生物, 成功地实现了不对称烯丙基取代反应与 2-氮杂-Cope 重 排的串联反应(Scheme 37), 以优秀的立体选择性和收 率获得了一系列 1,3-和 1,4-取代高烯丙胺化合物.

2016 年, 钮大文课题组 ${ }^{[114]}$ 以铱/银协同催化体系实 现了合成有机硼类化合物的新策略, 直接向目标分子中 立体选择性地引入了 “ $\mathrm{CH}_{2} \mathrm{~B}(\mathrm{OR})_{2}$ ” 基团，这种策略较 容易地合成了在嗍原子的 $\beta$ 位具有手性中心的化合物, 从谐二硼甲烷和烯丙基叔丁氧羰基酯出发合成了一系 列支链高烯丙基嗍酸酯(Scheme 38). 值得指出的是, 针 对不同类型底物, 他们使用了不同类型的手性配体, 其 中对邻位有大位阻取代基团的底物, 游书力课题组发展
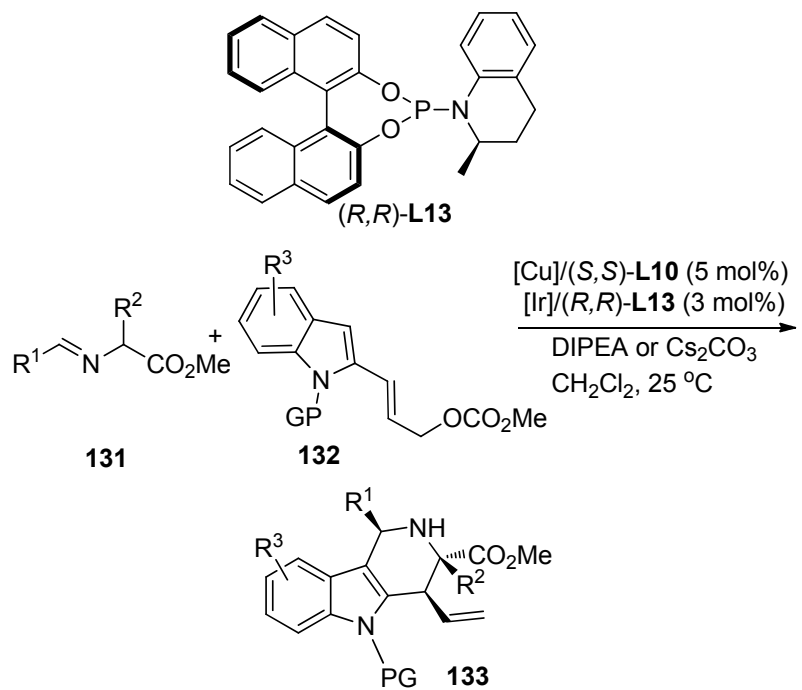

$75 \% \sim 98 \%$ yield $99 \%$ ee: $11: 1 \sim 20: 1 d r$

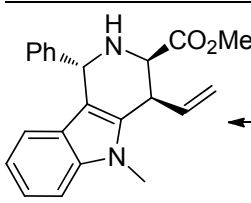

$(\mathrm{S}, R, S)-133 \mathrm{a}$

$98 \%$ yield $99 \%$ ee, $>20: 1 d r$

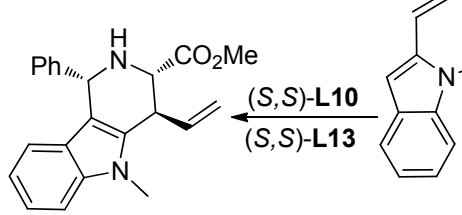

$(S, S, S)-133 a$ $94 \%$ yield $99 \%$ ee, $17: 1 d r$

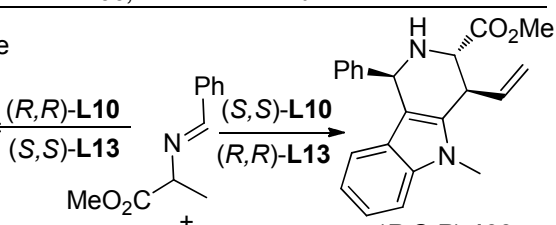
$R, S, R)-133 a$ $99 \%$ yield $99 \%$ ee, $>20: 1 d r$

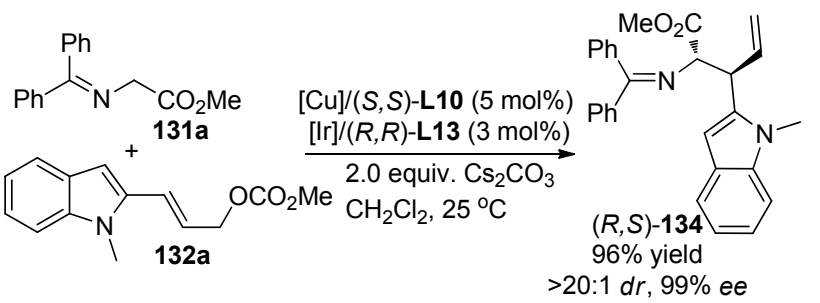

图式 36 铱/铜协同催化: 四氢- $\gamma$-咔啉衍生物的合成 Scheme 36 Synergetic $\mathrm{Ir} / \mathrm{Cu}$ catalysis: synthesis of tetrahydro- $\gamma$-carboline derivatives

的亚磷酰胺配体 L13 相较于 L6 也表现出了独特的优势. 对于缺电子类型底物, 使用了 Carreira 课题组发展的磷烯类型配体. 该反应具有较高的收率、较广的底物范围、 以及优秀的对映选择性.

\section{6 总结与展望}

综上所述，近十几年来金属铱与其他催化剂协同催 化的不对称烯丙基取代反应已经取得了重要进展，协同 催化策略的引入进一步丰富了该反应中亲核试剂的类 


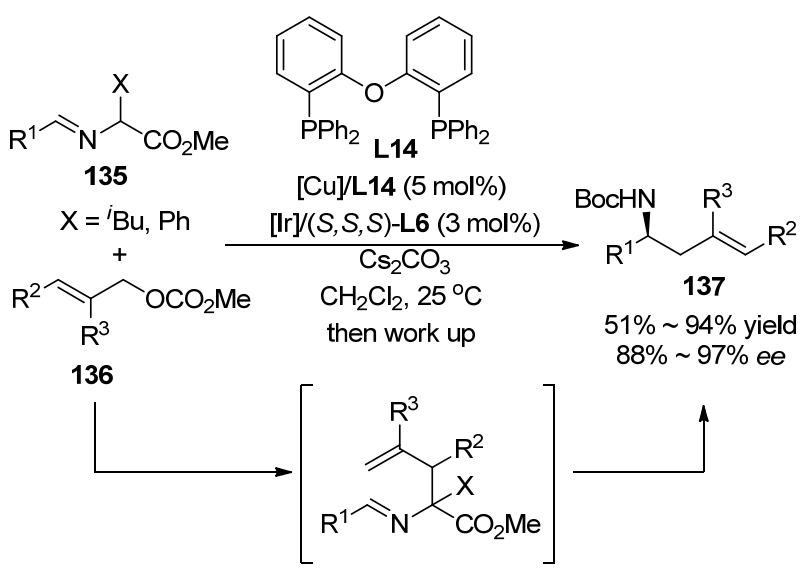

图式 37 铱/铜协同催化: 亚甲胺叶立德参与的烯丙基化/2-氮 杂-Cope 重排反应

Scheme 37 Synergetic Ir/Cu catalysis:: allylic alkylation/2-azaCope rearrangement of azomethine ylides

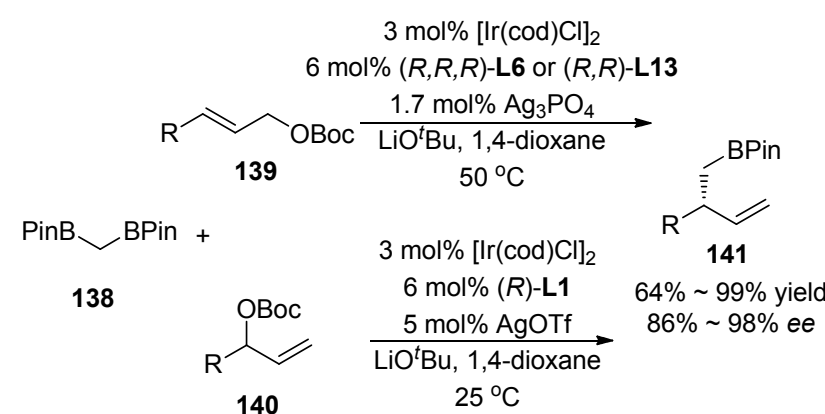

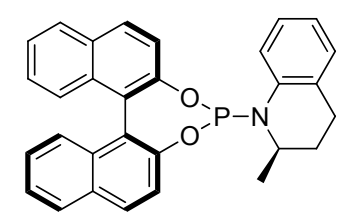

$(R, R)-\mathrm{L} 13$

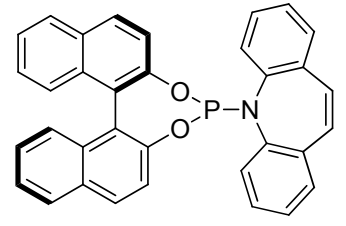

(R)-L1
图式 38 铱/银协同催化: $\beta$ 取代的手性烯丙基有机嗍酸酯的 合成

Scheme 38 Synergetic Ir/Ag catalysis: synthesis of chiral $\beta$-substituted allylic organoboronic esters

型(如醛类化合物、 $\alpha$-羊基酮、氨基酸酯席夫碱等), 实现 了多种金属铱单独催化作用下难以实现的不对称烯丙 基取代反应. 更为重要的是, 通过不同绝对构型的手性 催化剂的组合能够实现目标分子所有立体异构体的发 散性合成. 此外, 该类不对称烯丙基取代反应在 $\Delta^{9}$-tetrahydrocannabinols、(一)-actinophyllic acid、(一)-alstoscholarine、 heliannuols C (E) 和 heliespirones A (C) 等多种 天然产物和抗抑郁药物帕罗西汀的不对称合成中展现 出其重要应用价值. 尽管如此, 除金属铱与有机胺协同 催化体系应用较为全面之外, 金属铱与相转移催化剂、 布朗斯特酸、路易斯碱或其他过渡金属的协同催化体系
仅有零星报道，因此开发金属铱参与的新型协同催化体 系仍然是一个重要的研究方向. 此外, 目前的研究主要 集中于协同催化体系在单一不对称烯丙基取代反应中 的应用，设计开发基于不对称烯丙基取代的串联反应， 从而实现环状产物所有立体异构体的发散性合成，也是 将来值得研究的课题之一. 尤其需要指出的是, 该领域 研究的进展也将为一些重要的多手性中心活性药物分 子的合成及相应的手性药物发现提供新的合成方法和 策略.

\section{References}

[1] Trost, B. M.; van Vranken, D. L. Chem. Rev. 1996, 96, 395.

[2] Trost, B. M. Chem. Pharm. Bull. 2002, 50, 1.

[3] Trost, B. M.; Crawley, M. L. Chem. Rev. 2003, 103, 2921

[4] Milhau, L.; Guiry, P. J. Top. Organomet. Chem. 2011, 38, 95.

[5] Takeuchi, R.; Kashio, M. J. Am. Chem. Soc. 1998, 120, 8647.

[6] Takeuchi, R.; Ue, N.; Tanabe, K.; Yamashita, K.; Shiga, N. J. Am. Chem. Soc. 2001, 123, 9525.

[7] Takeuchi, R. Synlett 2002, 1954.

[8] Belda, O.; Moberg, C. Acc. Chem. Res. 2004, 37, 159.

[9] Trost, B. M. Org. Process Res. Dev. 2012, 16, 185.

[10] Moberg, C. Org. React. 2014, 84, 1.

[11] Trost, B. M.; Hachiya, I. J. Am. Chem. Soc. 1998, 120, 1104.

[12] Malkov, A. V.; Gouriou, L.; Lloyd-Jones, G. C.; Starý, I.; Langer, V.; Spoor, P.; Vinader, V.; Kočovský, P. Chem.-Eur. J. 2006, 12, 6910.

[13] Trost, B. M.; Zhang, Y. J. Am. Chem. Soc. 2007, 129, 14548.

[14] Trost, B. M.; Zhang, Y. Chem.-Eur. J. 2010, 16, 296.

[15] Trost, B. M.; Zhang, Y. Chem.-Eur. J. 2011, 17, 2916.

[16] Ozkal, E.; Pericas, M. A. Adv. Synth. Catal. 2014, 356, 711.

[17] Lloyd-Jones, G. C.; Pfaltz, A. Angew. Chem., Int. Ed. Engl. 1995, $34,462$.

[18] Matsushima, Y.; Onitsuka, K.; Kondo, T.; Mitsudo, T.; Takahashi, S. J. Am. Chem. Soc. 2001, 123, 10405.

[19] Onitsuka, K.; Matsushima, Y.; Takahashi, S. Organometallics 2005, 24, 6472.

[20] Onitsuka, K.; Okuda, H.; Sasai, H. Angew. Chem., Int. Ed. 2008, $47,1454$.

[21] Trost, B. M.; Rao, M.; Dieskau, A. P. J. Am. Chem. Soc. 2013, 135, 1869.

[22] Kawatsura, M.; Uchida, K.; Terasaki, S.; Tsuji, H.; Minakawa, M.; Itoh, T. Org. Lett. 2014, 16, 1470.

[23] Kanbayashi, N.; Hosoda, K.; Kato, M.; Takii, K.; Okamura, T.; Onitsuka, K. Chem. Commun. 2015, 51, 10895.

[24] Leahy, D. K.; Evans, P. A. In Modern Rhodium-Catalyzed Organic Reactions, Ed.: Evans, P. A., John Wiley \& Sons, Inc., New York, 2005; p. 191

[25] Evans, P. A.; Nelson, J. D. J. Am. Chem. Soc. 1998, 120, 5581.

[26] Hayashi, T.; Okada, A.; Suzuka, T.; Kawatsura, M. Org. Lett. 2003, $5,1713$.

[27] Kazmaier, U.; Stolz, D. Angew. Chem., Int. Ed. 2006, 45, 3072.

[28] Sidera, M.; Fletcher, S. P. Nat. Chem. 2015, 7, 935.

[29] Li, C.; Breit, B. Chem.-Eur. J. 2016, 22, 14655.

[30] Parveen, S.; Li, C.; Hassan, A.; Breit, B. Org. Lett. 2017, 19, 2326.

[31] Didiuk, M. T.; Morken, J. P.; Hoveyda, A. H. J. Am. Chem. Soc. 1995, 117, 7273 .

[32] Chung, K.-G.; Miyake, Y.; Uemura, S. J. Chem. Soc., Perkin Trans. $12000,15$.

[33] Kita, Y.; Kavthe, R. D.; Oda, H.; Mashima, K. Angew. Chem., Int. Ed. 2016, 55, 1098.

[34] Langlois, J. B.; Alexakis, A. Organomet. Chem. 2011, 38, 235.

[35] Malda, H.; van Zijl, A. W.; Arnold, L. A.; Feringa, B. L. Org. Lett. 2001, 3, 1169 . 
[36] Van Veldhuizen, J. J.; Campbell, J. E.; Giudici, R. E.; Hoveyda, A. H. J. Am. Chem. Soc. 2005, 127, 6877.

[37] Yoshikai, N.; Zhang, S.-L.; Nakamura, E. J. Am. Chem. Soc. 2008, 130, 12862

[38] Selim, K. B.; Matsumoto, Y.; Yamada, K.; Tomioka, K. Angew. Chem., Int. Ed. 2009, 48, 8733.

[39] Langlois, J.-B.; Alexakis, A. Adv. Synth. Catal. 2010, 352, 447.

[40] Shi, Y.; Jung, B.; Torker, S.; Hoveyda, A. H. J. Am. Chem. Soc. 2015, 137, 8948.

[41] You, H.; Rideau, E.; Sidera, M.; Fletcher, S. P. Nature 2015, 517, 351.

[42] Rideau, E.; You, H.; Sidera, M.; Claridge, T. D.W.; Fletcher, S. P. J. Am. Chem. Soc. 2017, 139, 5614.

[43] Tsuji, J.; Takahashi, H.; Morikawa, M. Tetrahedron Lett. 1965, 4387.

[44] Trost, B. M.; Strege, P. E. J. Am. Chem. Soc. 1977, 99, 1649.

[45] Trost, B. M.; Van Vranken, D. L. Chem. Rev. 1996, 96, 396.

[46] Trost, B. M.; Crawley, M. L. Chem. Rev. 2003, 103, 2921.

[47] Lu, Z.; Ma, S. Angew. Chem., Int. Ed. 2008, 47, 258.

[48] Takeuchi, R.; Kashio, M. Angew. Chem., Int. Ed. 1997, 36, 263.

[49] Janssen, J. P.; Helmchen, G. Tetrahedron Lett. 1997, 38, 8025.

[50] Hartwig, J. F.; Stanley, L. M. Acc. Chem. Res. 2010, 43, 1461.

[51] Liu, W.-B.; Xia, J.-B.; You, S.-L. Top. Organomet. Chem. 2011, 38,155 .

[52] Qu, J.; Helmchen, G. Acc. Chem. Res. 2017, 50, 2539.

[53] Cheng, Q.; Tu, H.; Zheng, C.; Qu J.; Helmchen, G.; You, S.-L. Chem. Rev. 2019, 119, 1855.

[54] Deng, Y.; Yang, W.; Yang, X.; Yang, D. Chin. J. Org. Chem. 2017, 37, 3039 (in Chinese) (邓颖颈，杨文，杨新，杨定乔，有机化学，2017, 37, 3039.)

[55] Shao, Z.; Zhang, H. Chem. Soc. Rev. 2009, 38, 2745.

[56] Zhong, C.; Shi, X. Eur. J. Org. Chem. 2010, 2010, 2999.

[57] Zhou, J. Chem. Asian J. 2010, 5, 422.

[58] Allen, A. E.; MacMillan, D. W. C. Chem. Sci. 2012, 3, 633.

[59] Du, Z.; Shao, Z. Chem. Soc. Rev. 2013, 42, 1337.

[60] Chen, D.-F.; Han, Z.-Y.; Zhou, X.-L.; Gong, L.-Z. Acc. Chem. Res. 2014, 47, 2365

[61] Inamdar, S. M.; Shinde, V.S.; Patil, N. T. Org. Biomol. Chem. 2015, 13, 8116 .

[62] Afewerki, S.; Córdova, A. Chem. Rev. 2016, 116, 13512.

[63] Zhang, M.-M.; Luo, Y.-L.; Lu, L.-Q.; Xiao, W.-J. Acta Chim. Sinica 2018, 76, 838 (in Chinese). (张毛毛, 骆元元, 陆良秋, 肖文精, 化学学报, 2018, 76, 838).

[64] Mukherjee, S.; Yang, J. W.; Hoffmann, S.; List, B. Chem. Rev. 2007, 107, 5471 .

[65] Melchiorre, P.; Marigo, M.; Carlone, A.; Bartoli, G. Angew. Chem., Int. Ed. 2008, 47, 6138

[66] Xu, L.-W.; Luo, J.; Lu, Y. Chem. Commun. 2009, 1807.

[67] Gualandi, A.; Mengozzi, L.; Wilson, C. M.; Cozzi, P. G. Chem Asian J. 2014, 9, 984.

[68] Afewerki, S.; Córdova, A. Chem. Rev. 2016, 116, 13512.

[69] Ibrahem, I.; Córdova, A. Angew. Chem., Int. Ed. 2006, 45, 1952.

[70] Krautwald, S.; Sarlah, D.; Schafroth, M. A.; Carreira, E. M. Science 2013, 340, 1065.

[71] Krautwald, S.; Schafroth, M. A.; Sarlah, D.; Carreira, E. M. J. Am Chem. Soc. 2014, 136, 3020

[72] Schafroth, M. A.; Zuccarello, G.; Krautwald, S.; Sarlah, D.; Carreira, E. M. Angew. Chem., Int. Ed. 2014, 53, 13898.

[73] Sandmeier, T.; Krautwald, S.; Zipfel, H. F.; Carreira, E. M. Angew. Chem., Int. Ed. 2015, 54, 14363 .

[74] For an example of water as a nucleophile in allylic substitution, see: Lüssem, B. J.; Gais, H.-J. J. Am. Chem. Soc. 2003, 125, 6066

[75] Sandmeier, T.; Goetzke, F. W.; Krautwald, S.; Carreira, E. M. J. Am. Chem. Soc. 2019, 141, 12212

[76] Sandmeier, T.; Carreira, E. M. Org. Lett. 2020, 22, 1135.

[77] Næsborg, L.; Halskov, K. S.; Tur, F.; Mønsted, S. M. N.; Jørgensen, K. A. Angew. Chem., Int. Ed. 2015, 54, 10193.
[78] Liang, X.; Zhang, T.-Y.; Meng, C.-Y.; Li, X.-D.; Wei, K.; Yang, Y.-R. Org. Lett. 2018, 20, 4575

[79] Yao, J.-N.; Liang, X.; Wei, K.; Yang, Y.-R. Org. Lett. 2019, 21, 8485.

[80] Zhang, M.-M.; Wang, Y.-N.; Wang, B.-C.; Chen, X.-W.; Lu, L.-Q.; Xiao, W.-J. Nat. Commun. 2019, 10, 2716.

[81] Liu, T.-Y.; Xie, M.; Chen, Y.-C. Chem. Soc. Rev. 2012, 41, 4101.

[82] Wei, Y.; Shi, M. Chem. Rev. 2013, 113, 6659.

[83] Pellissier, H. Tetrahedron 2017, 73, 2831.

[84] Chen, Z.-C.; Chen, Z.; Yang, Z.-H.; Guo, L.; Du, W.; Chen, Y.-C. Angew. Chem., Int. Ed. 2019, 58, 15021.

[85] Chen, P.; Li, Y.; Chen, Z.-C.; Du, W.; Chen, Y.-C. Angew. Chem., Int. Ed. 2020, 59, 7083.

[86] Shirakawa, S.; Maruoka, K. Angew. Chem., Int. Ed. 2013, 52, 4312.

[87] Chen, G.; Deng, Y.; Gong, L.-Z; Mi, A.; Cui, X.; Jiang, Y.; Choi, M. C.; Chan, A. S. Tetrahedron: Asymmetry 2001, 21, 1567.

[88] Nakoji, M.; Kanayama, T.; Okino, T.; Takemoto, Y. Org. Lett. 2001, 3, 3329 .

[89] Kanayama, T.; Yoshida, K.; Miyabe, H.; Kimachi, H.; Takemoto, Y. J. Org. Chem. 2003, 68, 6197.

[90] Hamilton, J. Y.; Sarlah, D.; Carreira, E. M. J. Am. Chem. Soc. 2013 , $135,3,994$.

[91] Hamilton, J. Y.; Sarlah, D.; Carreira, E. M. Angew. Chem., Int. Ed. 2013, 52, 7532.

[92] Su, Y.-L; Li, Y.-H.; Chen, Y.-G.; Han, Z.-Y. Chem. Commun. 2017, $53,1985$.

[93] Jiang, X.; Hartwig, J. F. Angew. Chem., Int. Ed. 2017, 56, 8887.

[94] Wei, L.; Xiao, L.; Wang, Z.-F.; Tao, H.-Y.; Wang, C.-J. Chin. J. Chem. 2020, 38, 82.

[95] Akiyama, T.; Itoh, J.; Yokota, K.; Fuchibe, K. Angew. Chem., Int. Ed. 2004, 43, 1566.

[96] Uraguchi, D.; Terada, M. J. Am. Chem. Soc. 2004, 126, 5356.

[97] Shen, D.; Chen, Q.; Yan, P.; Zeng, X.; Zhong, G. Angew. Chem., Int. Ed. 2017, 56, 3242.

[98] Jellerichs, B. G.; Kong, J. R.; Krische, M. J. J. Am. Chem. Soc. 2003, 125, 7758

[99] Birman, V. B.; Ulffman, E. W.; Jiang, H.; Li, X.; Kilbane, C. J. J. Am. Chem. Soc. 2004, 126, 12226.

[100] Purohit, V. C.; Matla, A. S.; Romo, D. J. Am. Chem. Soc. 2008, 130, 10478.

[101] Schwarz, K. J.; Amos, J. L.; Klein, J. C.; Do, D. T.; Snaddon, T. N. J. Am. Chem. Soc. 2016, 138, 5214

[102] Jiang, X.; Beiger, J. J.; Hartwig, J. F. J. Am. Chem. Soc. 2017, 139, 87

[103] Ye, K.-Y.; Cheng, Q.; Zhuo, C.-X.; Dai, L.-X.; You, S.-L. Angew. Chem., Int. Ed. 2016, 55, 8113.

[104] Singha, S.; Serrano, E.; Mondal, S.; Daniliuc, C. G.; Glorius, F. Nat. Catal. 2020, 3, 48.

[105] Huo, X.; He, R.; Zhang, X.; Zhang, W. J. Am. Chem. Soc. 2016 $138,11093$.

[106] He, R.; Liu, P.; Huo, X.; Zhang, W. Org. Lett. 2017, 19, 5513.

[107] Huo, X.; Zhang, J.; Fu, J.; He, R.; Zhang, W. J. Am. Chem. Soc 2018, 140, 2080

[108] Wei, L.; Zhu, Q.; Xu, S.-M.; Chang, X.; Wang, C.-J. J. Am. Chem. Soc. 2018, 140, 1508.

[109] Zhang, J.; Huo, X.; Li, B.; Chen, Z.; Zou, Y.; Sun, Z.; Zhang, W. Adv. Synth. Catal. 2019, 361, 1130.

[110] Jiang, X.; Boehm, P.; Hartwig, J. F. J. Am. Chem. Soc. 2018, 140, 1239.

[111] Xu, S.-M.; Wei, L.; Shen, C.; Xiao, L.; Tao, H.-Y.; Wang, C.-J. Nat Commun. 2019, 10, 5553.

[112] Liu, W.-B.; Zheng, C.; Zhuo, C.-X.; Dai, L.-X.; You, S.-L. J. Am Chem. Soc. 2012, 134, 4812

[113] Wei, L.; Zhu, Q.; Xiao, L.; Tao, H.-Y.; Wang, C.-J. Nat. Commun. 2019, 10, 1594.

[114] Zhan, M.; Li, R.-Z.; Mou, Z.-D.; Cao, C.-G.; Liu, J.; Chen, Y.-W.; Niu, D. ACS Catal. 2016, 6, 3381. 